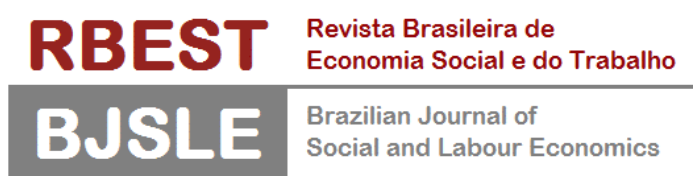

https://doi.org/10.20396/rbest.v2i.14205

\title{
DOSSIÊ: DESIGUALDADE
}

\section{Desigualdade de renda no Brasil, 1995-2019: diversas distribuições e o impacto do desemprego}

Rodolfo Hoffmann*

\begin{abstract}
Resumo
Neste artigo é analisada a distribuição da renda no Brasil de 1995 a 2019 com base nos dados da Pesquisa Nacional por Amostra de Domicílios (PNAD). Considera-se a distribuição da renda domiciliar per capita, a distribuição do rendimento do trabalho entre pessoas ocupadas e a distribuição do rendimento do trabalho entre pessoas economicamente ativas, argumentando que esta última é a mais apropriada se o foco da análise é o mercado de trabalho. Mostra-se que, embora haja diferenças metodológicas importantes entre a PNAD tradicional e a PNAD Contínua (com esta última captando melhor a desigualdade da distribuição da renda), é perfeitamente possível concatenar as séries de resultados das duas pesquisas. A análise da distribuição da renda domiciliar per capita de 1995 a 2019 mostra substancial redução da pobreza e da desigualdade até 2014. Infelizmente, no período 2014-2019 ocorre inversão no sentido dessas mudanças, perdendo-se cerca de $1 / 3$ da redução da desigualdade e $1 / 4$ da redução da pobreza conquistada no período anterior. Mostra-se que, em uma situação de crise como a que ocorreu no Brasil a partir de 2015, a análise limitada às pessoas ocupadas não mostra o real aumento da desigualdade.
\end{abstract}

Palavras-chave: Desigualdade; Distribuição de renda; Pobreza; Desemprego.

JEL: D31, I32, J01, J21.

* Escola Superior de Agricultura "Luiz de Queiroz", Universidade de São Paulo (ESALQ-USP), Brasil.

Orcid: http://orcid.org/0000-0002-2077-8202

E-mail: hoffmannr@usp.br

\section{$(\mathrm{CC})$ BY-NC-SA}

Nota: O autor agradece a colaboração de Josimar Gonçalves de Jesus. A parte do artigo relativa à distribuição da renda domiciliar per capita foi apresentada anteriormente num Texto para Discussão (Hoffmann, 2020a). 


\title{
Income inequality in Brazil, 1995-2019: diverse distributions and the impact of unemployment
}

\begin{abstract}
Using data from the National Households Sample Survey (PNAD), the paper analyses the income distribution in Brazil in the period 1995-2019. Three different distributions are analyzed: per capita household income, earnings by occupied persons and earnings of all economically active persons (attributing zero earnings to the unemployed). It is argued that this last measurement is the most appropriate in a study focused on the labor market. The methodological differences between the traditional PNAD (1995-2015) and the new "PNAD Continua" (2012-2019) are explained, showing that the new survey captures better the inequality of the income distribution; however, the results of the two surveys can be concatenated. The per capita household income series show that between 1995 and 2014 there was a substantial reduction in inequality and poverty. Unfortunately, in the following period, around $1 / 3$ of the previous inequality reduction and $1 / 4$ of the poverty reduction were lost. The paper shows that in an economic crisis, such as the one in Brazil after 2015, an analysis limited to the earnings distribution among occupied persons hides the increase in inequality.
\end{abstract}

Keywords: Inequality; Income distribution; Poverty; Unemployment.

\section{Desigualdad de ingreso en Brasil, 1995-2019: diversas distribuciones y el impacto del desempleo}

\section{Resumen}

En este artículo se analiza la distribución de ingreso en Brasil de 1995 a 2019 con base en los datos de la Encuesta Nacional por Muestra de Domicilios (PNAD). Se considera la distribución de ingresos domiciliar per cápita, la distribución del rendimiento del trabajo entre las personas ocupadas y la distribución del rendimiento laboral entre las personas económicamente activas, argumentando que esta última es la más apropiada si el foco de análisis es el mercado de trabajo. Se muestra que, a pesar de las importantes diferencias metodológicas entre la PNAD tradicional y la PNAD continua (la cual capta mejor la desigualdad de la distribución de ingreso), es perfectamente posible concatenar las series de resultados de las dos encuestas. El análisis de la distribución de ingreso domiciliar per cápita de 19952019 muestra una sustancial reducción de la pobreza y la desigualdad hasta 2014. Infelizmente, en el período 2014-2019 ocurre una reversión en el sentido de dichos cambios, perdiendo cerca de 1/3 de la reducción de la desigualdad y $1 / 4$ de la reducción de la pobreza, conquistadas en el período anterior. Se muestra que, en una situación de crisis como la que ocurrió en Brasil a partir de 2015, el análisis limitado a las personas ocupadas no muestra el real aumento de la desigualdade.

Palabras clave: Desigualdad; Distribución de ingreso; Pobreza; Desempleo.

\section{Inégalité des revenus au Brésil, 1995 à 2019: diverses distributions et impact du chômage}

\section{Résumé}

Cet article analyse la distribution des revenus au Brésil de 1995 a 2019 sur la base des données de I'Enquête nationale par sondage auprès des ménages (PNAD). La répartition du revenu du ménage par habitant, la répartition du revenu du travail parmi les personnes occupées et la répartition du revenu du travail parmi les personnes économiquement actives sont prises en compte, en faisant valoir que cette dernière est la plus appropriée si l'analyse porte sur le marché du travail. On montre que, s'il existe des différences méthodologiques importantes entre le PNAD traditionnel et le "PNAD contínua" (ce dernier saisissant mieux l'inégalité de la répartition des revenus), il est parfaitement possible de concaténer les séries de résultats des deux enquêtes. L'analyse de la distribution du revenu des ménages par habitant de 1995 à 2019 montre une réduction substantielle de la pauvreté et des inégalités jusqu'en 2014. Malheureusement, dans la période 2014-2019, il y a une inversion dans le sens de ces changements, perdant environ $1 / 3$ de la réduction des inégalités et $1 / 4$ de la réduction de la pauvreté obtenue au cours de la période précédente. Il est montré que, dans une situation de crise comme celle survenue au Brésil depuis 2015, l'analyse limitée aux salariés ne montre pas la réelle augmentation des inégalités.

Mots clés: Inégalités; Répartition des revenus; Pauvreté; Chômage. 


\section{Introdução}

Pressupõe-se que seja dispensável argumentar que a distribuição da renda é tema fundamental da análise socioeconômica de uma sociedade mercantil. O tema ganhou especial destaque no Brasil quando, durante a ditadura militar, a comparação de dados do Censo Demográfico de 1970 com o de 1960 mostrou a ocorrência de substancial crescimento da desigualdade (Andrada \& Boianovsky, 2020). A desigualdade permaneceu muito elevada até o fim do milênio, com análises cada vez mais pormenorizadas tornadas possíveis pela disponibilidade de dados fornecidos pelo Instituto Brasileiro de Geografia e Estatística (IBGE), com destaque para a Pesquisa Nacional por Amostra de Domicílios (PNAD), e o progresso da computação eletrônica, com uso disseminado de microdados. Os dados da PNAD mostraram tendência decrescente da desigualdade nos primeiros 15 anos do novo milênio, mas ela voltou a crescer após 2015.

Este artigo analisa a evolução de três tipos de distribuição da renda: (1) distribuição da renda domiciliar per capita (RDPC), (2) distribuição da renda do trabalho entre pessoas ocupadas (POC) e (3) distribuição da renda do trabalho entre pessoas economicamente ativas (PEA).

São utilizados os microdados da Pesquisa Nacional por Amostra de Domicílios (PNAD) tradicional de 1995 a 2015 e da PNAD Contínua (PNADC) de 2012 a 2019. Na primeira parte deste artigo analisa-se a evolução das distribuições no Brasil de 2012 a 2019, com base na PNADC. Na segunda parte, para ter uma visão para um período maior, consideram-se tanto os dados da PNAD Contínua para o período 2012-2019 como os dados da PNAD tradicional de 1995 a 2015.

\section{0 período de 2012 a 2019}

Para o período 2012-2019 são utilizados dados da Entrevista 1 da PNAD Contínua anual, considerando o rendimento habitual ou, mais especificamente, o rendimento habitual do trabalho e o rendimento efetivo de outras fontes.

Todos os valores monetários foram expressos em reais $(R \$)$ do quarto trimestre de 2019 com base no Índice Nacional de Preços ao Consumidor (INPC). Para os dados da PNAD tradicional considerou-se, para cada ano, a média geométrica dos índices de setembro e outubro e para a PNAD Contínua a média geométrica dos índices referentes aos três meses do trimestre associado a cada observação nos microdados.

\subsection{A distribuição da RDPC de 2012 a 2019}


A análise da distribuição da RDPC permite considerar quase toda a população e todos os tipos de renda captados na PNAD. ${ }^{1}$ É a distribuição comumente utilizada quando se procura avaliar o nível de pobreza ou bem-estar da população e é praticamente equivalente à distribuição da renda familiar per capita. ${ }^{2}$

Tabela 1. Média, quartis e percentis 90 e 95 da distribuição da RDPC (em R $\$$ do $4^{\circ}$ trimestre de 2019). Brasil: 2012-2019.

\begin{tabular}{ccccccc}
\hline Ano & Média & Q1 & Mediana & Q3 & P90 & P95 \\
\hline 2012 & 1310 & 416 & 780 & 1401 & 2608 & 4151 \\
2013 & 1345 & 442 & 824 & 1431 & 2756 & 4231 \\
2014 & 1398 & 472 & 869 & 1502 & 2806 & 4413 \\
2015 & 1348 & 457 & 841 & 1468 & 2723 & 4159 \\
2016 & 1331 & 429 & 805 & 1423 & 2734 & 4255 \\
2017 & 1337 & 429 & 809 & 1431 & 2696 & 4277 \\
2018 & 1401 & 434 & 844 & 1502 & 2843 & 4430 \\
2019 & 1419 & 444 & 870 & 1516 & 2833 & 4378 \\
\hline
\end{tabular}

Fonte: IBGE. PNAD Contínua. Elaboração própria.

Figura 1. Evolução da média e da mediana da distribuição da RDPC, Brasil, 2012-2019 (em $R \$$ do $4^{\circ}$ trimestre de 2019)

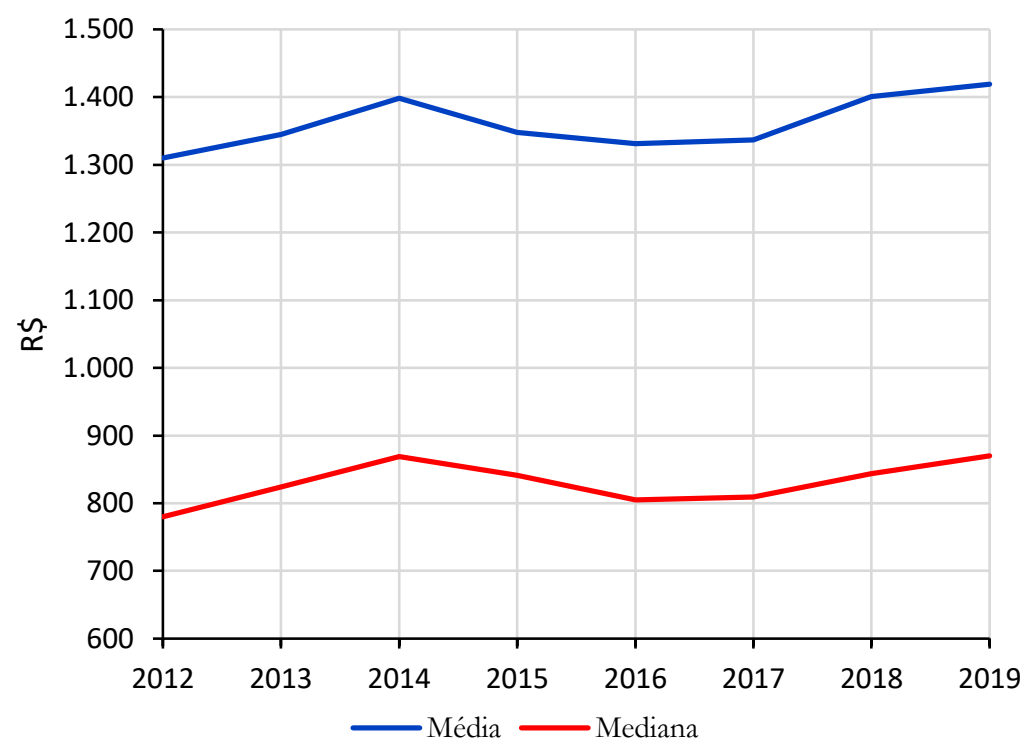

${ }^{1}$ São considerados apenas os domicílios particulares permanentes e, ao calcular a RDPC, excluemse os empregados domésticos e seus parentes residentes no domicílio do empregador, que, conforme a PNADC de 2019, representavam apenas 0,04\% do total de 209,5 milhões de pessoas residentes nos domicílios analisados.

2 De acordo com a PNADC de 2019, apenas 0,5\% das pessoas consideradas na distribuição da RDPC não são parentes da pessoa de referência dos domicílios. 
A Tabela 1 e a Figura 1 mostram que os valores médio e mediano da RDPC cresceram de 2012 a 2014, caíram de 2014 a 2016 e depois se recuperaram, atingindo, em 2019, valores praticamente iguais aos de 2014.

A Tabela 2 e as Figuras 2, 3, 4 e 5 mostram a evolução de várias medidas da desigualdade da distribuição de RDPC no Brasil de 2012 a 2019. ${ }^{3}$

Tabela 2. Índice de Gini, T de Theil e seu dual, porcentagens da renda total declarada apropriada pelos $50 \%$ mais pobres (50-), pelo décimo mais rico $(10+)$ e pelo vigésimo mais rico (5+), conforme dados da PNADC. Brasil: 2012-2019.

\begin{tabular}{ccccccc}
\hline Ano & Gini & T & Dual do T & $50-$ & $10+$ & $5+$ \\
\hline 2012 & 0,540 & 0,592 & 0,447 & 15,8 & 43,0 & 30,7 \\
2013 & 0,533 & 0,566 & 0,432 & 16,2 & 42,3 & 29,8 \\
2014 & 0,527 & 0,550 & 0,423 & 16,6 & 41,8 & 29,3 \\
2015 & 0,524 & 0,547 & 0,421 & 16,6 & 41,4 & 29,1 \\
2016 & 0,537 & 0,575 & 0,437 & 15,9 & 42,4 & 29,9 \\
2017 & 0,538 & 0,584 & 0,443 & 15,8 & 42,5 & 30,2 \\
2018 & 0,545 & 0,602 & 0,452 & 15,5 & 43,1 & 30,6 \\
2019 & 0,543 & 0,600 & 0,451 & 15,6 & 42,9 & 30,6 \\
\hline
\end{tabular}

Figura 2. Evolução do índice de Gini e da medida T de Theil da desigualdade da distribuição da RDPC no Brasil, 2012-2019

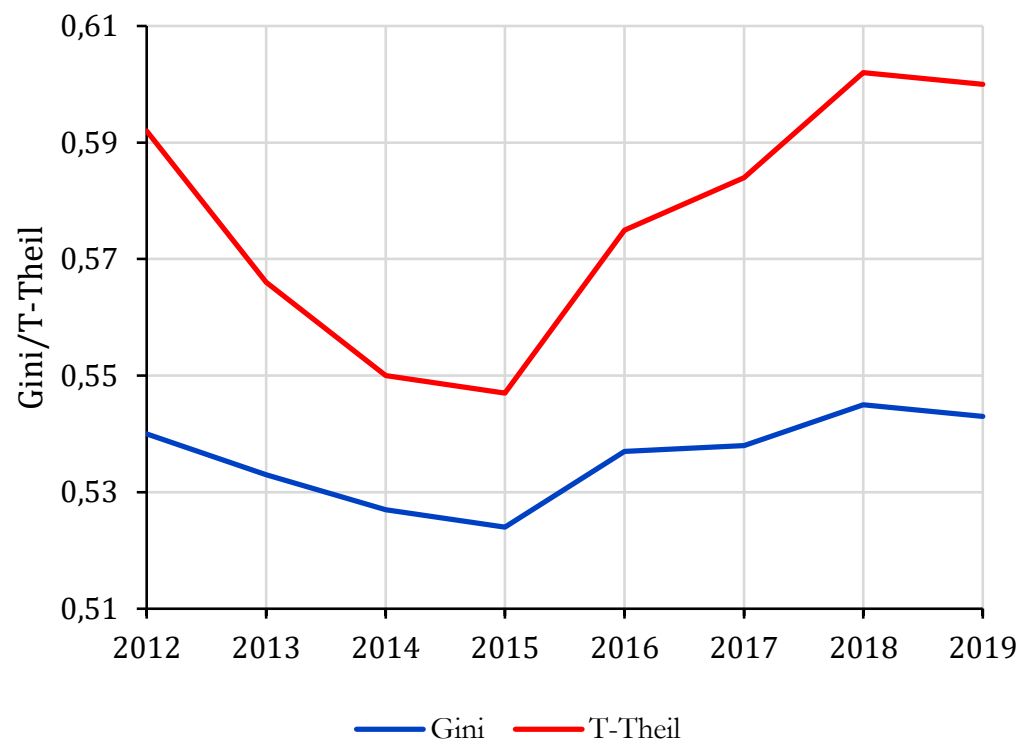

${ }^{3}$ Em comparação com o índice de Gini, o T de Theil é uma medida mais sensível a mudanças na cauda superior da distribuição. $O$ dual do $T$ de Theil é dado por $\mathrm{U}_{\mathrm{T}}=1-\exp (-\mathrm{T})$, ficando limitado ao intervalo de zero a menos que 1, da mesma maneira que o índice de Gini. 
A evolução do índice de Gini e da medida T de Theil na Figura 2 mostra que a desigualdade da distribuição da RDPC caiu cada vez mais lentamente de 2012 a 2015, subiu de 2015 a 2018, com crescimento mais intenso de 2015 a 2016, e diminuiu ligeiramente de 2018 a 2019. A evolução das outras medidas de desigualdade ilustrada nas Figuras 3, 4 e 5 é semelhante, cabendo ressaltar que a razão entre médias do centésimo mais rico e da metade mais pobre apresenta seu valor mais baixo em 2014 e sobe um pouco de 2018 a 2019 .

Figura 3. Evolução da porcentagem da renda total apropriada pelo décimo mais rico (10+) Brasil, 2012-2019

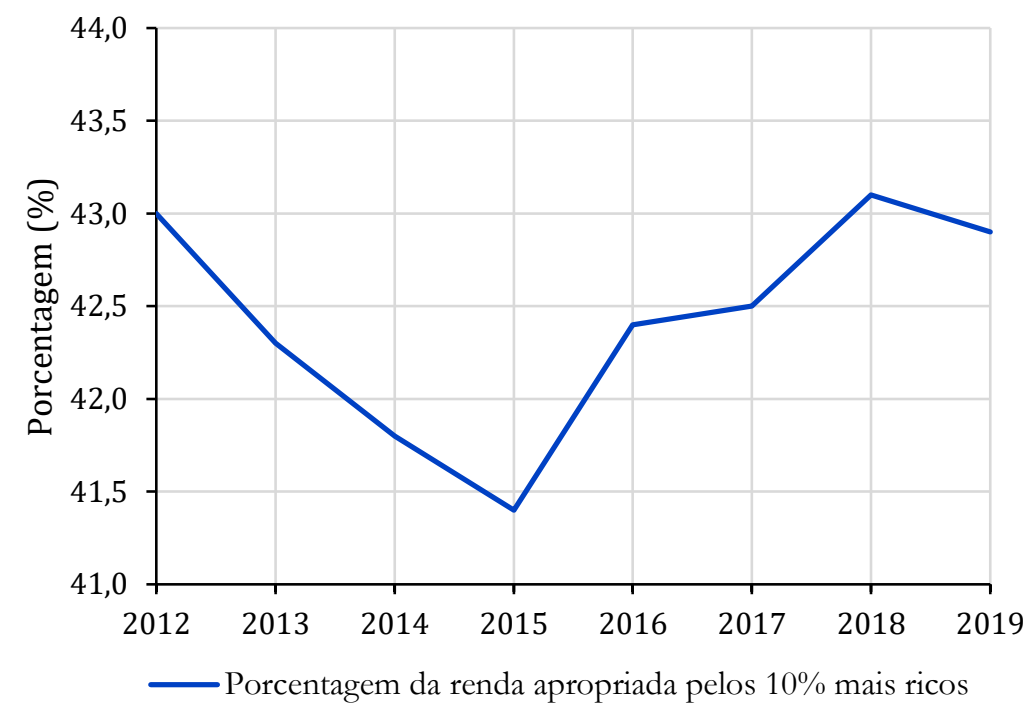

Figura 4. Evolução da razão entre rendas médias do décimo mais rico e dos $40 \%$ mais pobres Brasil, 2012-2019

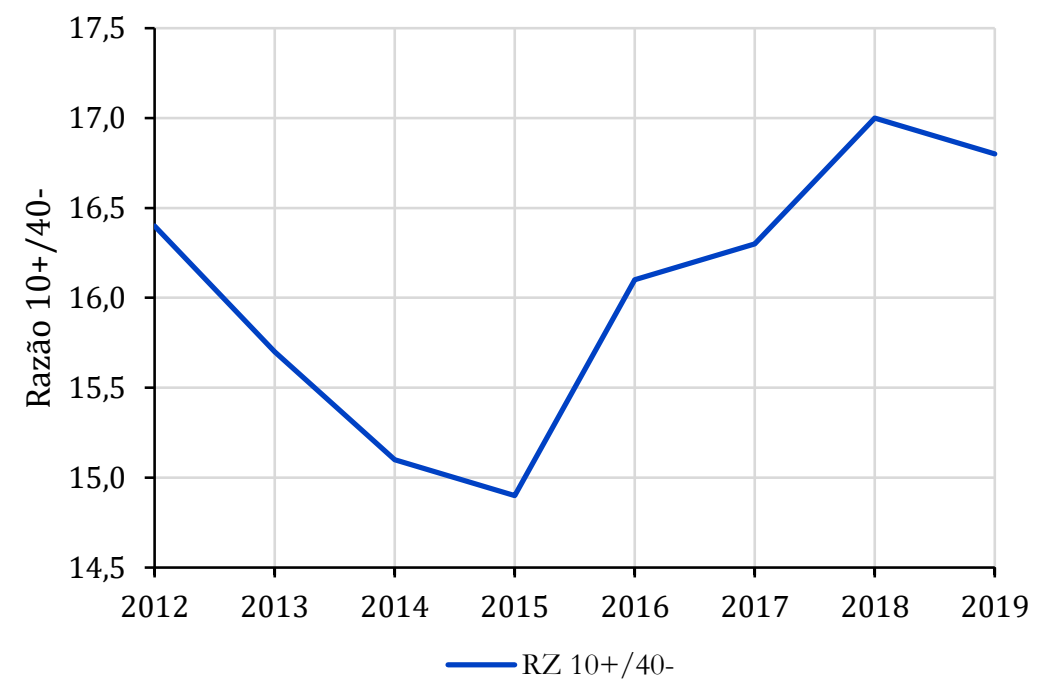


Figura 5. Evolução da razão entre rendas médias do centésimo mais rico e da metade mais pobre Brasil, 2012-2019

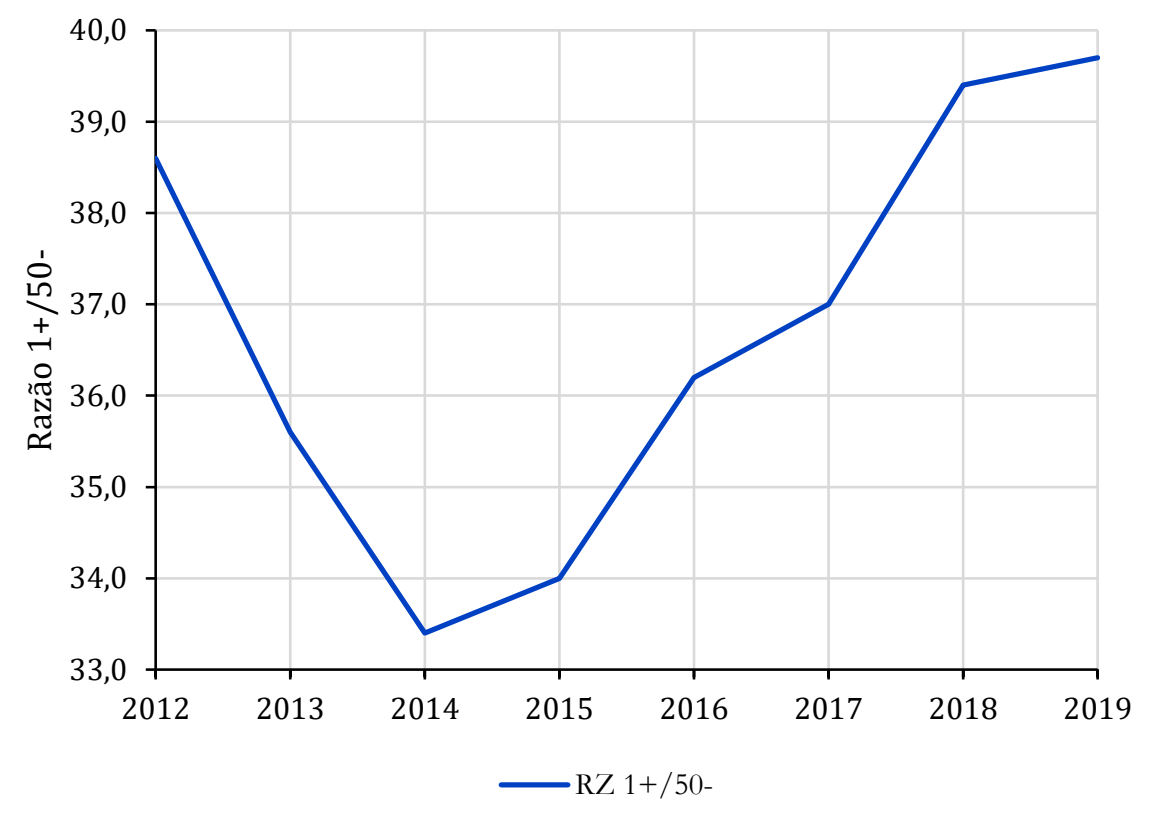

A Tabela 3 e as Figuras 6 e 7 mostram a variação de algumas medidas de pobreza. A medida de pobreza mais simples é a proporção de pobres $(H)$, mas ela só capta a extensão da pobreza. A razão de insuficiência de renda (I) é o complemento da razão entre a renda média dos pobres e a linha de pobreza, indicando em quanto a renda dos pobres fica, em média, abaixo da linha de pobreza; trata-se, portanto, de uma medida da intensidade da pobreza. O produto HI é, então, uma medida que leva em consideração tanto a extensão como a intensidade da pobreza. O valor HI é a mesma coisa que o índice de Foster, Greer e Thorbecke com parâmetro 1. O índice de Foster, Greer e Thorbecke com parâmetro 2, que indicamos por FGT, é ainda mais sofisticado, levando em consideração a desigualdade da distribuição da renda entre os pobres, pois no seu cálculo se considera o quadrado da insuficiência de renda de cada pessoa pobre, o que significa dar mais peso aos pobres mais pobres. $^{4}$

\footnotetext{
${ }^{4}$ Fórmulas de cálculo podem ser encontradas em Hoffmann, Botassio e Jesus (2019). Em princípio, as medidas $\mathrm{H}$, HI e FGT podem variar de zero a 1 . Mas por ser um produto de duas frações, o valor de $\mathrm{HI}$ já tende a ser mais baixo; $\mathrm{HI}=0,25$ se metade da população for pobre e a renda média dos pobres for metade da linha de pobreza. O valor da medida FGT tende a ser ainda menor. Se não houver nenhuma desigualdade entre os pobres, $\mathrm{FGT}=\mathrm{H} \cdot \mathrm{I}^{2}$. Assim, se $\mathrm{H}=0,5$ e todos os pobres ganham metade da linha de pobreza, temos FGT $=0,125$, mesmo se tratando, obviamente, de elevado grau de pobreza. Mas o mais relevante, na análise apresentada neste texto, é a variação das medidas ao longo do tempo.
} 
Tabela 3. Proporção de pobres $(\mathrm{H})$ e índice FGT para diferentes linhas de pobreza ( $z=400, z=500$ e $z=600$, em $R \$$ do $4^{0}$ trimestre de 2019). Brasil: 2012-2019.

\begin{tabular}{ccccccc}
\hline Ano & $H(400)$ & $H(500)$ & $H(600)$ & FGT(400) & FGT(500) & FGT(600) \\
\hline 2012 & 0,238 & 0,321 & 0,386 & 0,059 & 0,080 & 0,102 \\
2013 & 0,222 & 0,301 & 0,368 & 0,053 & 0,072 & 0,094 \\
2014 & 0,204 & 0,281 & 0,346 & 0,047 & 0,065 & 0,084 \\
2015 & 0,213 & 0,292 & 0,354 & 0,050 & 0,069 & 0,090 \\
2016 & 0,232 & 0,309 & 0,378 & 0,059 & 0,079 & 0,101 \\
2017 & 0,231 & 0,294 & 0,376 & 0,063 & 0,082 & 0,104 \\
2018 & 0,227 & 0,294 & 0,364 & 0,063 & 0,082 & 0,102 \\
2019 & 0,221 & 0,283 & 0,354 & 0,062 & 0,081 & 0,101 \\
\hline
\end{tabular}

Fonte: IBGE. PNAD Contínua. Elaboração própria.

As Figuras 6 e 7 mostram redução da pobreza de 2012 a 2014 e a reversão dessa conquista nos dois anos seguintes. Se for adotada uma linha de pobreza de $\mathbf{R} \$ 400$ per capita, a proporção de pobres (H) diminui ligeiramente de 2016 a 2019, mas o índice FGT, que leva em consideração o grau de insuficiência de renda dos pobres, cresce de 2016 a 2017 e em 2019 está em nível superior ao de 2016.

Figura 6. Evolução da proporção de pobres para linhas de pobreza de $R \$ 400, R \$ 500$ e $R \$ 600$ per capita Brasil, 2012-2019

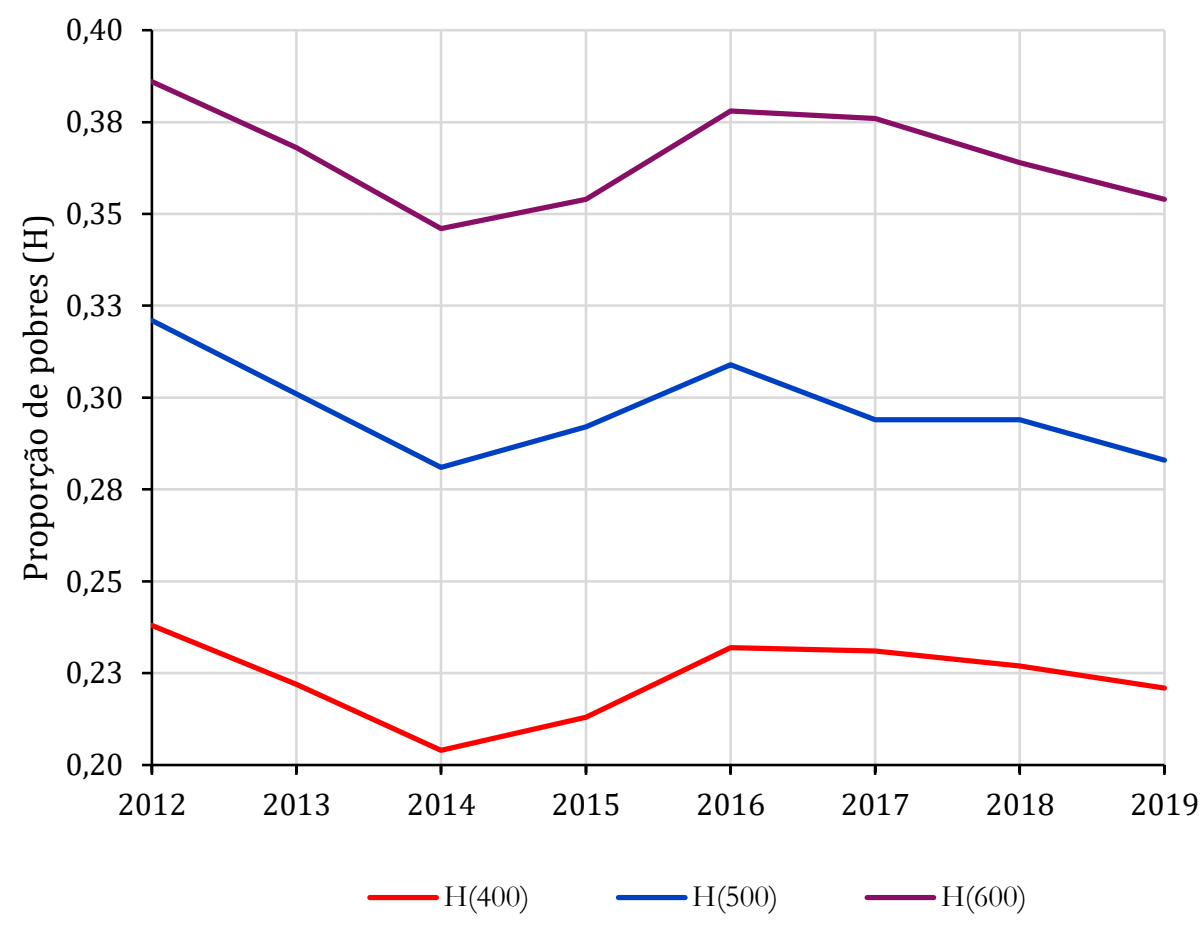


Figura 7. Valor do índice de pobreza de Foster, Greer e Thorbecke (FGT) para linhas de pobreza de $\mathrm{R} \$ 400, \mathrm{R} \$ 500$ e $\mathbf{R} \$ 600$ per capita, Brasil, 2012-2019

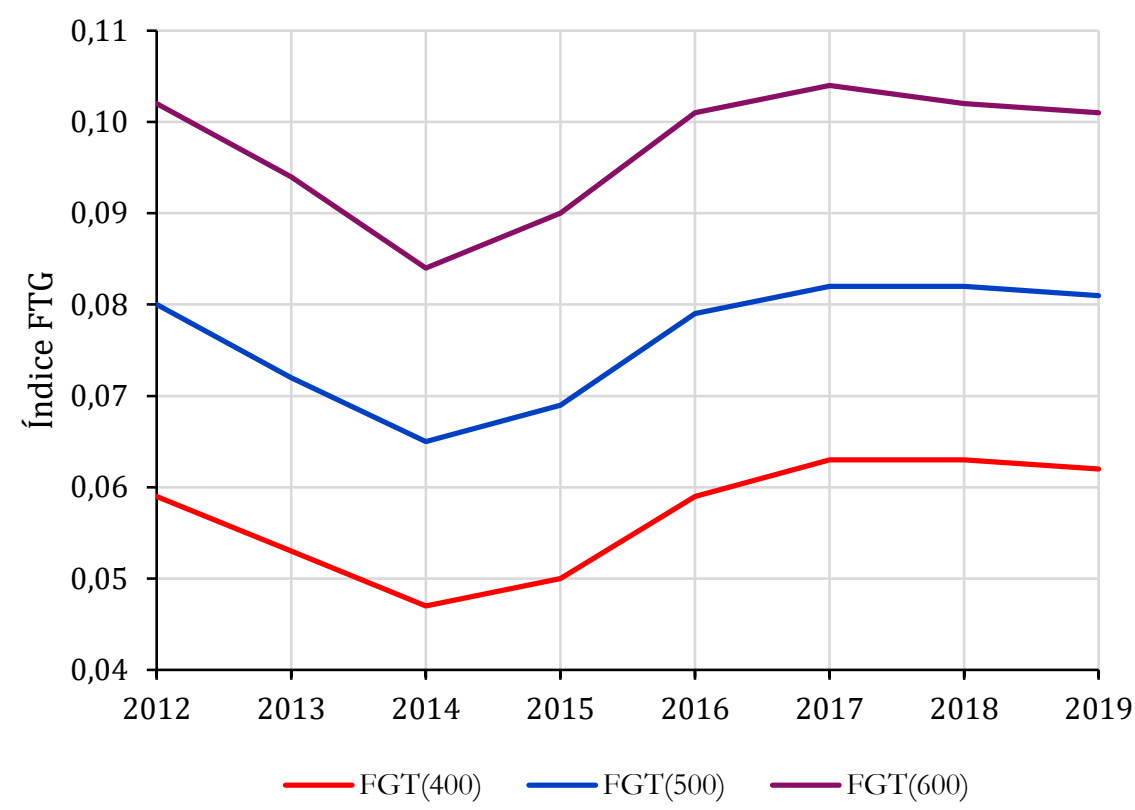

Figura 8. Curvas de quantis e médias (M, linhas horizontais) das distribuições da RDPC (em R $\$$ do $4^{\circ}$ trimestre de 2019), Brasil, 2012, 2014 e 2019

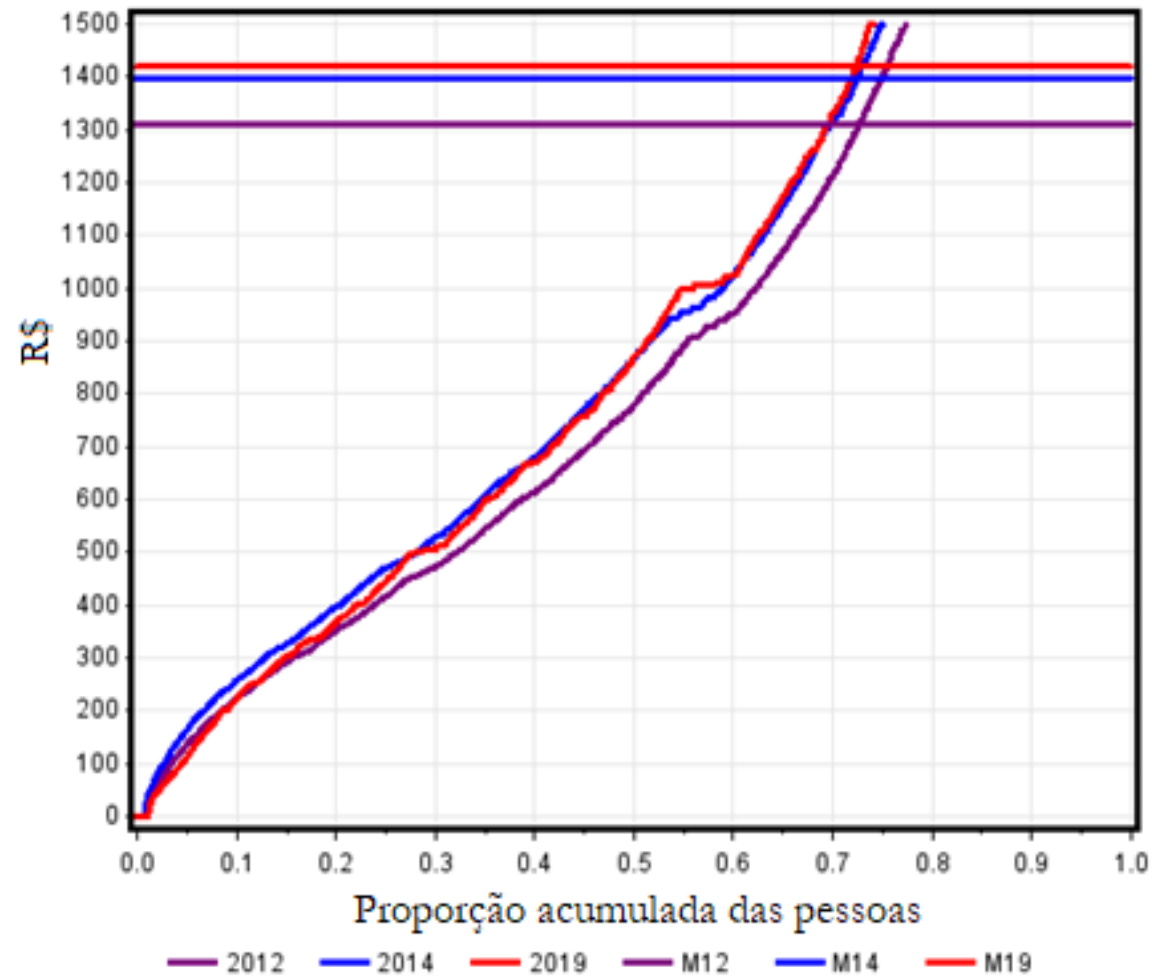


O exame das curvas de quantis da RDPC, apresentadas na Figura 8, permite entender melhor a natureza da variação do nível de pobreza entre 2012, 2014 e 2019. Consideremos a variação de 2014 a 2019. Escolher a linha de pobreza corresponde a fixar atenção na respectiva ordenada da curva de quantis; a proporção de pobres $(H)$ é, então, a respectiva abscissa da curva de quantis. Observa-se, na Figura 8, que para uma linha de pobreza de $\mathrm{R} \$ 1400$ a proporção de pobres atingiria cerca de 72\%, mas seria, em 2019, ligeiramente menor que em 2014. Entretanto, para qualquer linha de pobreza abaixo de $\mathrm{R} \$$ 450, a proporção de pobres em 2019 é maior que em 2014.

\subsection{A distribuição da renda do trabalho entre pessoas ocupadas e entre pessoas economicamente ativas de 2012 a 2019}

Pode ser de interesse analisar a distribuição do rendimento do trabalho entre as pessoas ocupadas (ou população ocupada - POC), se, por exemplo, o objetivo do pesquisador for o estudo do efeito das características pessoais e do próprio emprego sobre a remuneração obtida. Em algumas situações o pesquisador é obrigado a se limitar ao uso do rendimento do trabalho porque não há informações sobre os outros tipos de renda (aposentadorias, pensões, doações, transferências etc.). Nesta seção do artigo será considerado o que o IBGE denomina "rendimento mensal habitual de todos os trabalhos para pessoas de 14 anos ou mais de idade", sendo importante ter em mente que isso inclui o rendimento obtido por trabalhadores por conta própria e por empregadores. No caso de um fazendeiro, por exemplo, o valor declarado pode incluir lucro, renda da terra e até juros sobre o capital próprio, embora haja forte tendência de que os valores sejam subdeclarados. Se o pesquisador estiver interessado na distribuição da renda obtida na forma de salário, deve limitar a análise às pessoas ocupadas cuja posição na ocupação é a de empregado.

A distribuição do rendimento do trabalho entre pessoas ocupadas tem o grave defeito de ignorar os desempregados. Pode ser razoável utilizá-la para descrever a evolução da distribuição do rendimento do trabalho em um período no qual a taxa de desemprego tenha permanecido estável. Mas se ocorreu um enorme crescimento do desemprego, como no Brasil de 2014 a 2017, a evolução da distribuição para POC será enganosa. É importante, então, incluir na análise os desempregados, considerando toda a população economicamente ativa. Para isso, atribui-se aos desempregados um "rendimento do trabalho" igual a zero.

Observa-se, na Tabela 4, que o rendimento mensal médio do trabalho na POC no final do período analisado é maior do que nos anos iniciais, mas quando se considera toda a PEA, o rendimento médio final é praticamente igual ao inicial. As séries de valores do rendimento mediano também mostram que limitar a análise à POC produz uma evolução mais favorável por desconsiderar o crescimento do desemprego. 
Tabela 4. Valores médio e mediano do rendimento do trabalho da POC e da PEA (em R\$ do $4^{0}$ trimestre de 2019). Brasil: 2012-2019.

\begin{tabular}{lllll}
\hline \multirow{2}{*}{ Ano } & \multicolumn{2}{c}{ Rendimento médio } & \multicolumn{2}{c}{ Rendimento mediano } \\
& POC & PEA & POC & PEA \\
\hline 2012 & 2226 & 2058 & 1316 & 1208 \\
2013 & 2296 & 2125 & 1385 & 1265 \\
2014 & 2381 & 2211 & 1358 & 1320 \\
2015 & 2277 & 2071 & 1410 & 1260 \\
2016 & 2276 & 2009 & 1338 & 1195 \\
2017 & 2272 & 1981 & 1302 & 1187 \\
2018 & 2343 & 2055 & 1386 & 1248 \\
2019 & 2333 & 2056 & 1414 & 1212 \\
\hline
\end{tabular}

Fonte: IBGE. PNAD Contínua. Elaboração própria.

A Tabela 5 mostra a evolução de várias medidas de desigualdade: o índice de Gini, o T de Theil, a porcentagem do rendimento total apropriada pelo décimo mais rico (\% $10+$ ) e a razão entre as rendas médias dos $10 \%$ mais ricos e dos $40 \%$ mais pobres (Razão $10+/ 40-$ ). Obviamente, por incluir os desempregados com rendimento do trabalho igual a zero, a desigualdade na PEA é sempre maior do que na POC. Mas, o mais importante é notar a diferença de comportamento na evolução das duas séries: para a POC, a desigualdade no final do período é semelhante à inicial, mas quando se considera toda a PEA, a desigualdade no final é sempre substancialmente maior do que no ano inicial.

Tabela 5. Medidas de desigualdade da distribuição do rendimento do trabalho entre POC e entre PEA. Brasil: 2012-2019

\begin{tabular}{ccccccccc}
\hline \multirow{2}{*}{ Ano } & \multicolumn{2}{c}{ Índice de Gini } & \multicolumn{2}{c}{ T de Theil } & \multicolumn{2}{c}{$\% 10+$} & \multicolumn{2}{c}{ Razão 10+/40- } \\
& POC & PEA & POC & PEA & POC & PEA & POC & PEA \\
\hline 2012 & 0,508 & 0,545 & 0,545 & 0,624 & 41,80 & 43,40 & 12,81 & 16,19 \\
2013 & 0,502 & 0,539 & 0,528 & 0,605 & 41,40 & 42,90 & 12,41 & 15,59 \\
2014 & 0,501 & 0,537 & 0,522 & 0,596 & 41,40 & 42,90 & 12,44 & 15,45 \\
2015 & 0,494 & 0,539 & 0,510 & 0,605 & 40,60 & 42,40 & 11,94 & 15,90 \\
2016 & 0,501 & 0,560 & 0,526 & 0,651 & 41,20 & 43,80 & 12,32 & 18,17 \\
2017 & 0,501 & 0,565 & 0,528 & 0,665 & 41,20 & 44,00 & 12,34 & 19,11 \\
2018 & 0,509 & 0,570 & 0,555 & 0,686 & 41,90 & 44,50 & 13,00 & 19,71 \\
2019 & 0,509 & 0,568 & 0,555 & 0,682 & 42,00 & 44,50 & 12,98 & 19,33 \\
\hline
\end{tabular}

Fonte: IBGE. PNAD Contínua. Elaboração própria.

Barbosa (2019) analisa dados trimestrais da PNADC para a distribuição do rendimento do trabalho entre todas as pessoas entre 18 e 65 anos (incluindo pessoas que não estão na PEA). Ele obtém uma evolução da desigualdade no período 2012-2019 que é semelhante à obtida aqui para a PEA. A delimitação da idade evita incluir muitas pessoas 
aposentadas ou ainda exclusivamente dedicadas a estudar, mas é claro que é grande o número de pessoas não economicamente ativas incluídas, cujo rendimento do trabalho é nulo. Isso faz com que o índice de Gini calculado para dados de 2017, 2018 e 2019 ultrapasse 0,68, enquanto o índice de Gini para distribuição do rendimento do trabalho na PEA obtido aqui (Tabela 5) não ultrapasse 0,57. A evolução das características das duas distribuições do rendimento do trabalho (na PEA ou entre todas as pessoas entre 18 e 65 anos) será semelhante se permanecer constante a proporção de pessoas entre 18 e 65 anos que não é economicamente ativa. Se o foco da análise é o mercado de trabalho, parece ser mais apropriado analisar a distribuição do rendimento do trabalho na PEA.

É útil saber que, se o índice de Gini para a POC é $G_{O}$ e são incluídas pessoas com rendimento do trabalho nulo que constituem uma fração $S$ do novo total, o índice de Gini passa a $\operatorname{ser}^{5} G_{E}=S+(1-S) G_{O}$.

Tabela 6. Proporção de pobres e medida FGT da distribuição do rendimento do trabalho entre POC e entre PEA, adotando linha de pobreza de $R \$ 420$ (em $R \$$ do $4^{\circ}$ trimestre de 2019). Brasil: 2012-2019.

\begin{tabular}{lllll}
\hline \multirow{2}{*}{ Ano } & \multicolumn{2}{c}{ Proporção de pobres } & \multicolumn{2}{c}{ Medida FGT } \\
& POC & PEA & POC & PEA \\
\hline 2012 & 0,078 & 0,148 & 0,021 & 0,095 \\
2013 & 0,069 & 0,139 & 0,019 & 0,092 \\
2014 & 0,074 & 0,140 & 0,017 & 0,087 \\
2015 & 0,074 & 0,157 & 0,018 & 0,107 \\
2016 & 0,074 & 0,183 & 0,019 & 0,134 \\
2017 & 0,078 & 0,196 & 0,021 & 0,147 \\
2018 & 0,086 & 0,199 & 0,022 & 0,142 \\
2019 & 0,091 & 0,199 & 0,022 & 0,138 \\
\hline
\end{tabular}

Fonte: IBGE. PNAD Contínua. Elaboração própria.

Ao calcular medidas de pobreza para a distribuição da renda na POC ou na PEA é conveniente adotar uma linha de pobreza que fique, ao longo de todo o período analisado, sempre abaixo ou sempre acima do valor real do salário mínimo, para evitar descontinuidades que dificultam a interpretação da evolução da pobreza. Como o salário mínimo é um valor muito frequente nos dados sobre rendimento do trabalho na PNAD, ${ }^{6}$ há grande aumento nas medidas de pobreza quando a linha de pobreza passa de valor um pouco menor para um

\footnotetext{
5 Ver Hoffmann, Botassio e Jesus (2019, p. 45). Na p. 103 desse livro encontra-se expressão semelhante para o dual do T de Theil.

6 Na PNAD Contínua anual de 2019, 8,8\% dos rendimentos habituais do trabalho das pessoas ocupadas declarados eram exatamente iguais ao salário mínimo corrente (RS 998,00). Como ainda há a tendência de declarar números redondos, nada menos do que 15,3\% declararam valor de $\mathrm{R} \$ 998$ a $\mathrm{R} \$ 1.000$.
} 
pouco maior que o salário mínimo. Como na segunda parte deste artigo será analisado todo o período de 1995 a 2019 e o salário mínimo real em setembro-outubro de 1996 foi R\$ 445 (em reais do quarto trimestre de 2019), adotou-se uma linha de pobreza de R $\$ 420$ por mês. A tabela 6 mostra a evolução da proporção de pobres e da medida FGT na POC e na PEA de 2012 a 2019. Obviamente, a medida de pobreza é sempre maior na PEA do que na POC e, devido ao enorme crescimento do desemprego de 2014 a 2017, o crescimento da pobreza no período é muito maior quando se considera a PEA do que quando a análise é limitada à POC.

\section{0 período de 1995 a 2019}

Para obter uma visão da evolução da distribuição da renda no Brasil em um prazo mais amplo, vamos incluir na análise os dados da PNAD tradicional de 1995 a 2015. Há diferenças metodológicas importantes entre a PNAD Contínua e a tradicional. Na PNAD tradicional eram coletados os valores dos rendimentos no mês de referência, que foi sempre setembro no período 1995-2015; na PNAD Contínua a coleta é feita ao longo do ano. Assim, a PNAD Contínua capta variações estacionais nos rendimentos que não podem ser captadas pela PNAD tradicional (Hoffmann, Jesus \& Almeida, 2018, pp. 8-9):

Outra diferença importante ocorre na estratificação da amostra. Na PNAD tradicional havia três estágios de seleção: municípios (unidades primárias), setores censitários (unidades secundárias) e domicílios (unidades terciárias) (IBGE, 2014a). Já na PNAD Contínua há apenas dois estágios no processo de amostragem: no primeiro são selecionadas as unidades primárias de amostragem (UPAs, formadas por um ou mais setores censitários) e no segundo são selecionados os domicílios dentro de cada UPA (IBGE, 2014b). Esse procedimento, sem o estágio de seleção de municípios, faz que a PNAD Contínua capte melhor a variabilidade geográfica (espacial).

A PNAD tradicional só inclui todo o território nacional a partir de 2004. Antes a pesquisa não abrangia a área rural da antiga Região Norte. Quando se utilizam dados anteriores a 2004, é usual excluir dos microdados do período 2004-2015 as informações referentes à área rural da antiga Região Norte. Mas isso traria um ruído adicional à comparação entre as duas PNAD. Optou-se, então, por apresentar resultados de três séries:

(a) Dados da PNAD tradicional de 1995 a 2015, excluindo as informações da área rural da antiga Região Norte;

(b) Dados da PNAD tradicional para todo o Brasil de 2004 a 2015;

(c) Dados da PNAD Contínua de 2012 a 2019. 


\subsection{Evolução da RDPC de 1995 a 2019}

Na Figura 9, a evolução da RDPC média para a série (a) está em vermelho, para a série (b) em laranja e para a série (c) em roxo. Como a área rural da antiga Região Norte é relativamente pobre, a linha laranja fica ligeiramente abaixo da linha vermelha, mas a evolução dessas duas séries é praticamente idêntica. No período 2012-2015, a média para a série (c) fica sempre acima da média para série (b), indicando que a renda habitual coletada na PNAD Contínua capta melhor a renda total do que a renda declarada na PNAD tradicional.

Diferente do que acontece com as médias, a mediana da série (c) (linha verde) não fica, no período 2012-2015, sempre acima da mediana da série (b) (linha azul claro). Isso está relacionado ao fato de que a PNAD Contínua capta mais desigualdade do que a PNAD tradicional. Mais desigualdade se associa com mais assimetria positiva, que se reflete em maior distância relativa entre a média e a mediana da distribuição.

Figura 9. Evolução da média e da mediana da distribuição da RDPC e do salário mínimo (SM) (em R $\$$ do $4^{0}$ trimestre de 2019), Brasil, 1995-2019

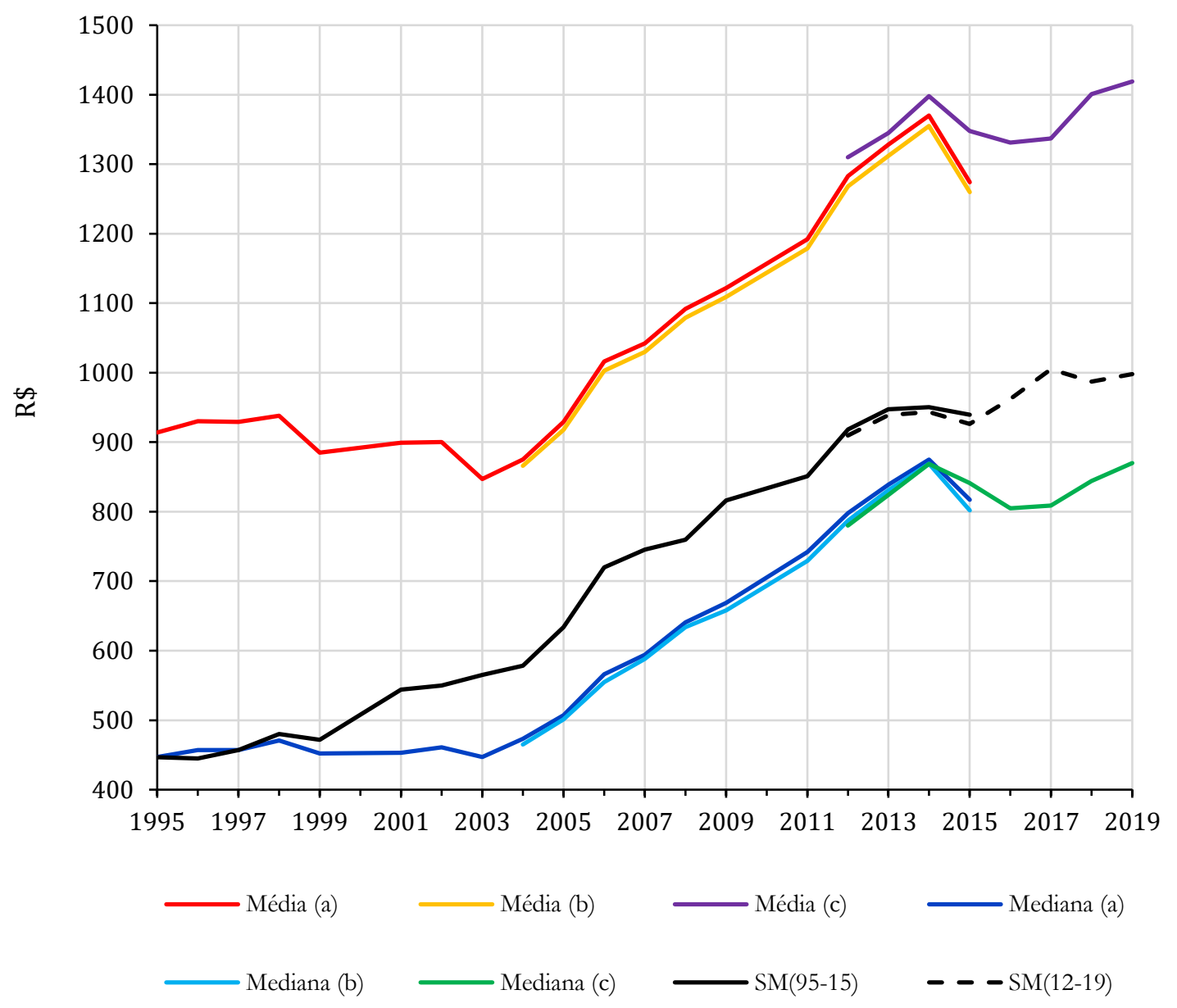


A Figura 9 mostra, também, a evolução do salário mínimo real (SMR) de 1995 a 2019, sempre em reais ( $R \$$ ) de out./nov./dez. de 2019. Uma série para o período 1995-2015 (linha preta contínua) considera o salário vigente em setembro (mês de referência da PNAD tradicional), deflacionado pela média geométrica dos valores do INPC em setembro e outubro. Outra série, para o período 2012-2019 (linha preta tracejada), considera o salário mínimo no quarto trimestre de cada ano, deflacionado da mesma maneira que os rendimentos declarados na PNAD Contínua referentes ao mesmo trimestre. Observa-se, na Figura 9, que no início do período analisado (1995-1998) a RDPC mediana é igual ou semelhante ao salário mínimo e que nos anos seguintes o salário mínimo passa a superar a mediana de forma consistente. $\mathrm{Na}$ qualidade de "farol" para os rendimentos mais baixos, o substancial crescimento do salário mínimo real no período contribuiu para a redução da desigualdade da distribuição da RDPC.

A Figura 10 mostra a evolução, de 1995 a 2019, dos três quartis da distribuição da RDPC, para os três tipos de série. Acompanhando a variação na desigualdade, verifica-se que a razão entre o terceiro e o primeiro quartil é igual ou maior do que 4,2 nos quatro primeiros anos do período analisado, cai para menos de 3,2 em 2014 e sobe para mais de 3,4 em 2018 e 2019. No que se refere à mediana e ao salário mínimo, a Figura 10 repete informações que já constam na Figura 9.

Figura 10. Evolução dos três quartis da distribuição da RDPC e do salário mínimo (SM) (em R\$ do $4^{\circ}$ trimestre de 2019), Brasil, 1995-2019

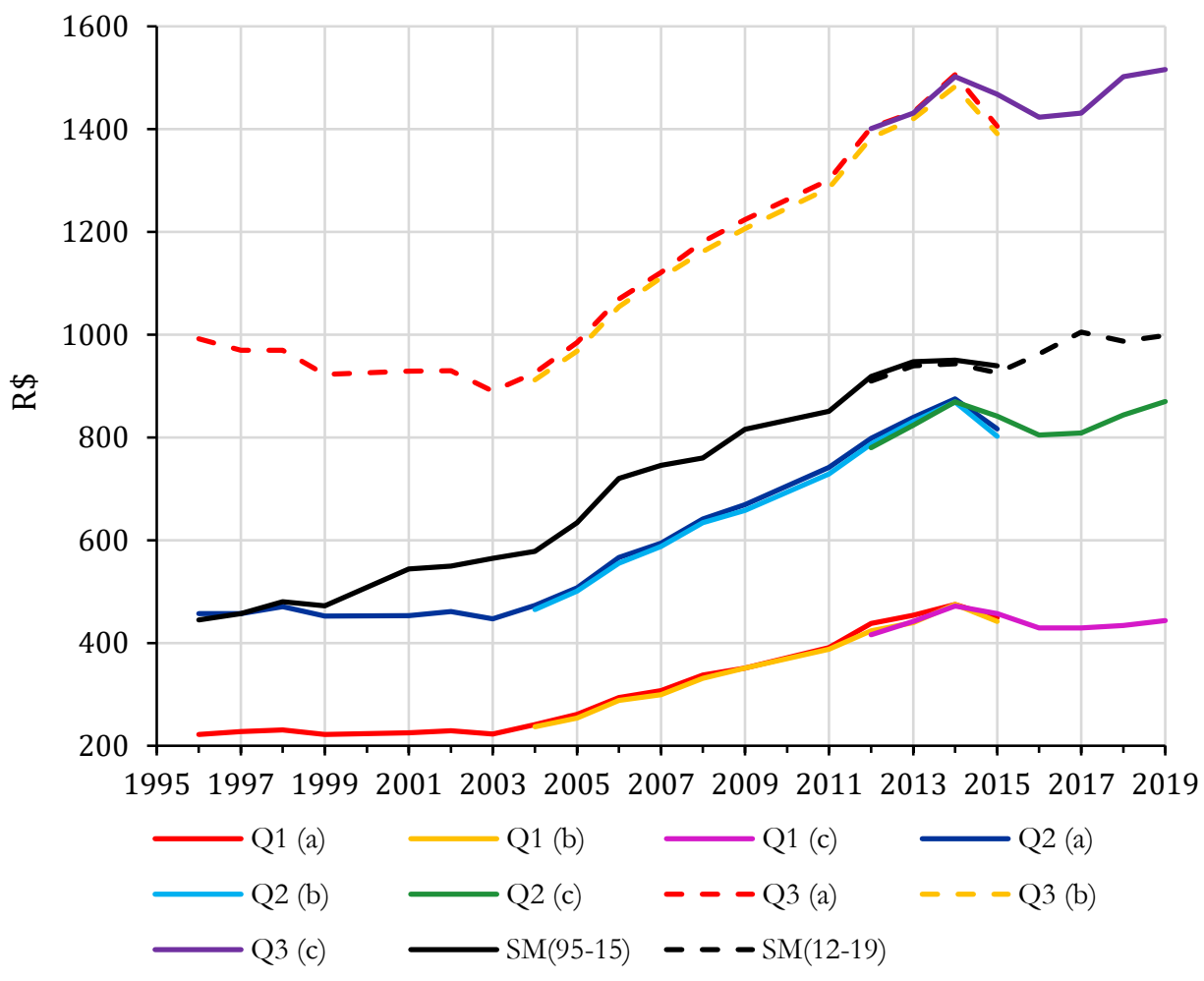


A Figura 11 mostra, para os três tipos de série, a evolução de duas medidas da desigualdade da distribuição da renda per capita: o índice de Gini e o T de Theil. A exclusão da área rural da antiga Região Norte reduz ligeiramente a desigualdade, mas o comportamento das medidas de desigualdade ao longo do tempo praticamente não é afetado. Para o período 2012-2015, durante o qual dispomos tanto de dados da PNAD Contínua como da PNAD tradicional, as duas medidas de desigualdade para a PNAD Contínua (linha rosa para o índice de Gini e linha verde para o T) são sempre substancialmente maiores que os valores correspondentes para a PNAD tradicional, mostrando como, devido às diferenças no processo de amostragem já assinaladas, a PNAD Contínua revela mais desigualdade da distribuição da RDPC do que a PNAD tradicional. ${ }^{7}$ A Figura 11 mostra que ocorreu grande redução da desigualdade de 2001 a 2015, mas que parte substancial dessa conquista foi perdida nos 3 anos seguintes. Figura 11. Evolução do índice de Gini e da medida T de Theil da desigualdade da distribuição da RDPC
Brasil, 1995-2019

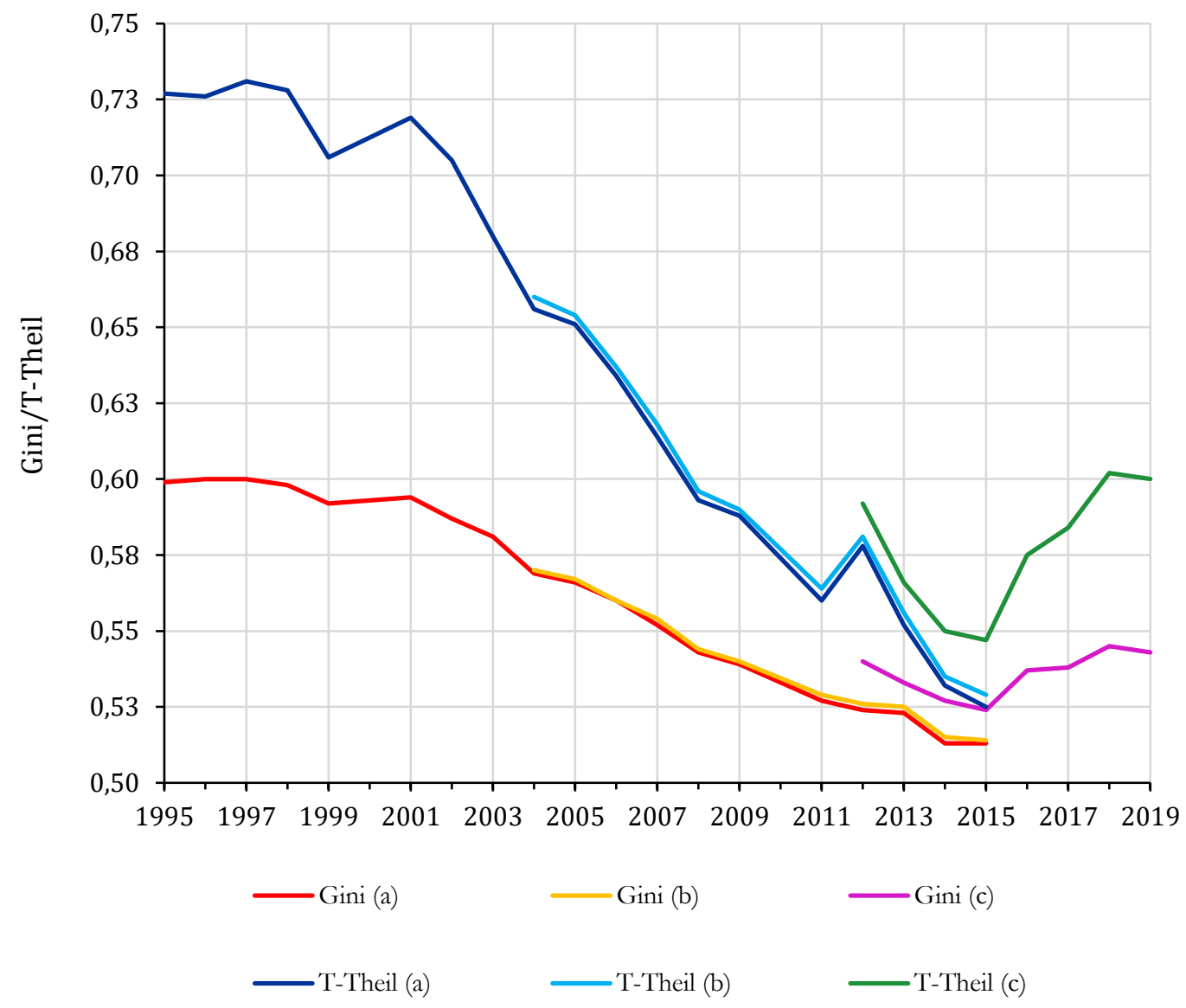

${ }^{7}$ Almeida (2019) já constatara claramente esse fato, analisando dados da distribuição da renda do trabalho por pessoa ocupada e por pessoa economicamente ativa. 
A evolução da desigualdade é essencialmente a mesma quando se consideram duas outras medidas de desigualdade: a razão entre médias do décimo mais rico e dos $40 \%$ mais pobres (Figura 12) e a razão entre médias do centésimo mais rico e da metade mais pobre (Figura 13).

Figura 12. Evolução da razão entre médias do décimo mais rico e dos $40 \%$ mais pobres Brasil, 1995-2019

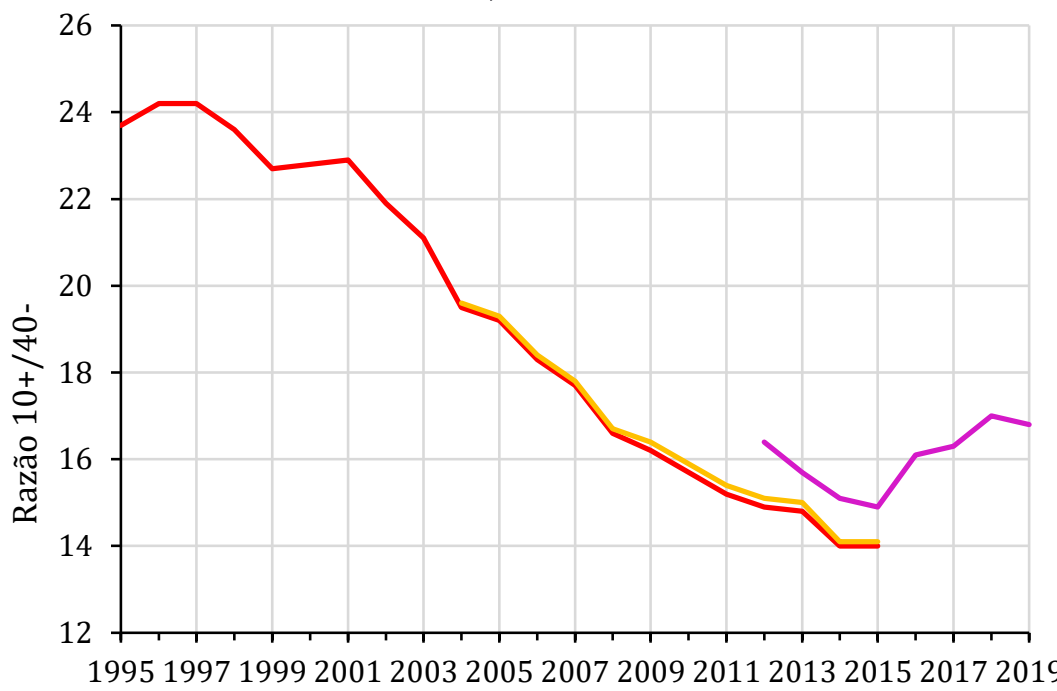

$\longrightarrow \mathrm{RZ} 10+/ 40-$ (a) $\quad \mathrm{RZ} 10+/ 40-$ (b) $\quad \mathrm{RZ} 10+/ 40-(\mathrm{c})$

Figura 13. Evolução da razão entre médias do centésimo mais rico e da metade mais pobres Brasil, 1995-2019

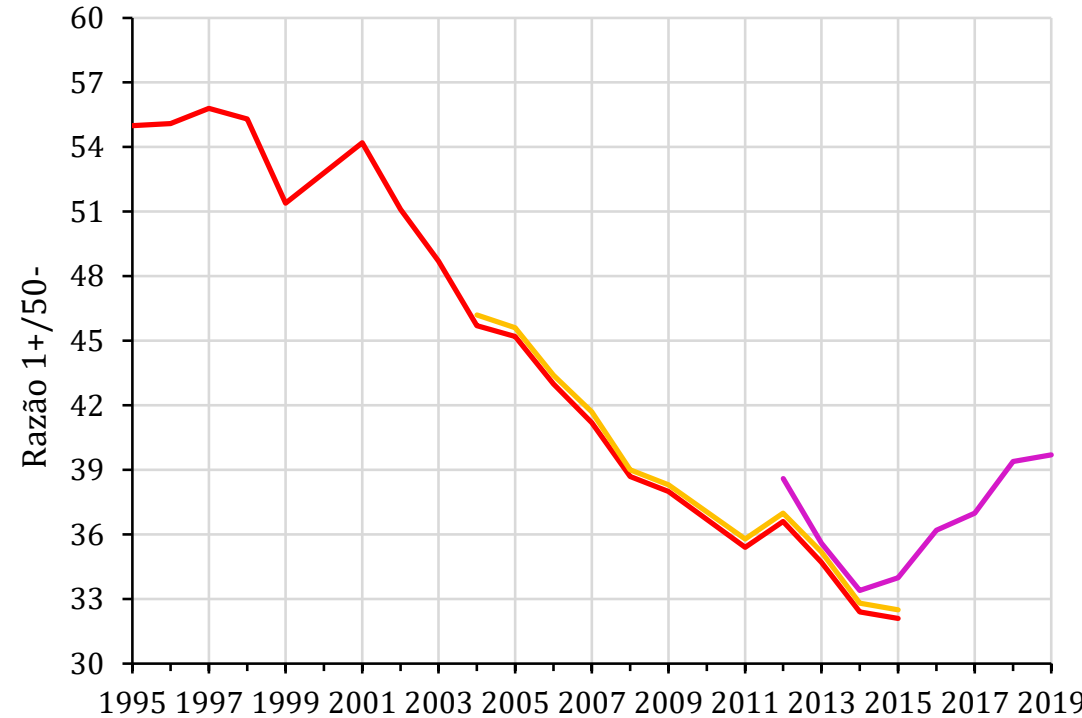

$\longrightarrow \mathrm{RZ} 1+/ 50-(\mathrm{a}) \longrightarrow \mathrm{RZ} 1+/ 50-(\mathrm{b})-\mathrm{RZ} 1+/ 50-(\mathrm{c})$ 
As Figuras 14 a 17 mostram a evolução de várias medidas de pobreza de 1995 a 2019, considerando linhas de pobreza de $R \$ 400$ ou de $R \$ 200$ per capita, em reais ( $R \$$ ) do quarto trimestre de 2019.

Vimos que a desigualdade da distribuição da RDPC no Brasil caiu a partir de 2001. Mas ocorreu queda da renda média de 2002 a 2003, causando aumento da pobreza. Então, conforme se observa nas Figuras 14 a 17, a pobreza passa a cair apenas a partir de 2003. Ocorre grande redução da pobreza de 2003 a 2014 e um aumento substancial de 2014 a 2017.

A Figura 17 mostra a evolução da pobreza no Brasil de 1995 a 2019, considerando o índice FGT para uma linha de pobreza de R\$200. Grosso modo o índice cai de 0,06 no início da série para 0,02 em 2014, mas logo sobe para 0,03 em 2017 e permanece nesse nível até 2019.

Um quarto de toda a redução da pobreza conquistada de 1995 a 2014 é perdida de 2014 a 2017, permanecendo nesse novo patamar até 2019. Hoje (maio de 2020) a atenção está focada na crise associada à pandemia do coronavírus. Infelizmente, a situação socioeconômica do País já era muito frágil (qualificativos menos comedidos podem ser empregados) antes dessa nova crise. Não se deve cometer o erro de atribuir toda a miséria à pandemia.

Figura 14. Evolução da proporção de pobres $(H)$ e da medida $H I$, adotando uma linha de pobreza de $R \$ 400$ (em R $\$$ do $4^{0}$ trimestre de 2019), Brasil, 1995-2019

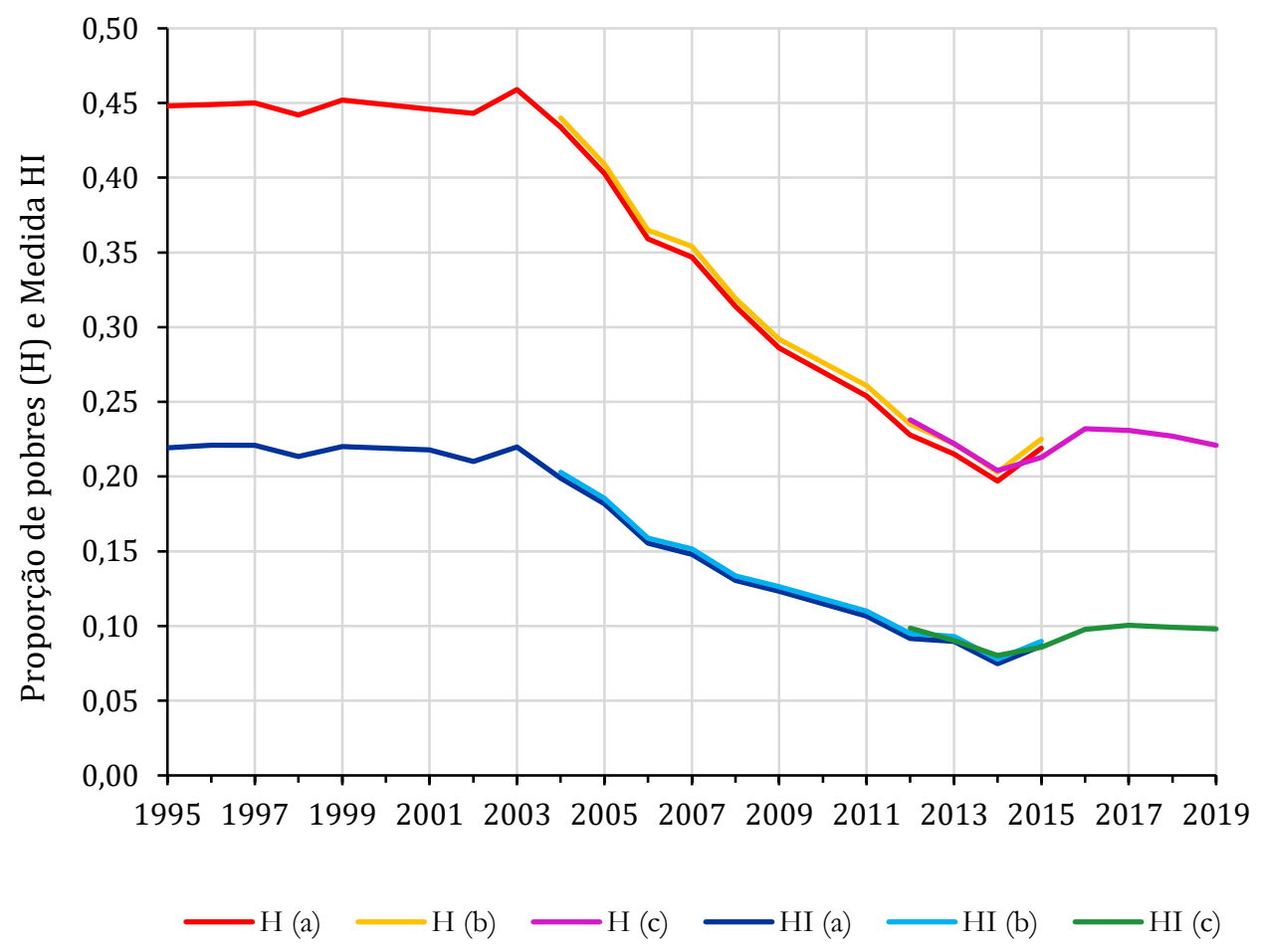


Figura 15. Evolução do índice de pobreza FGT adotando uma linha de pobreza de R\$400 (em R\$ do $4^{\circ}$ trimestre de 2019), Brasil, 1995-2019

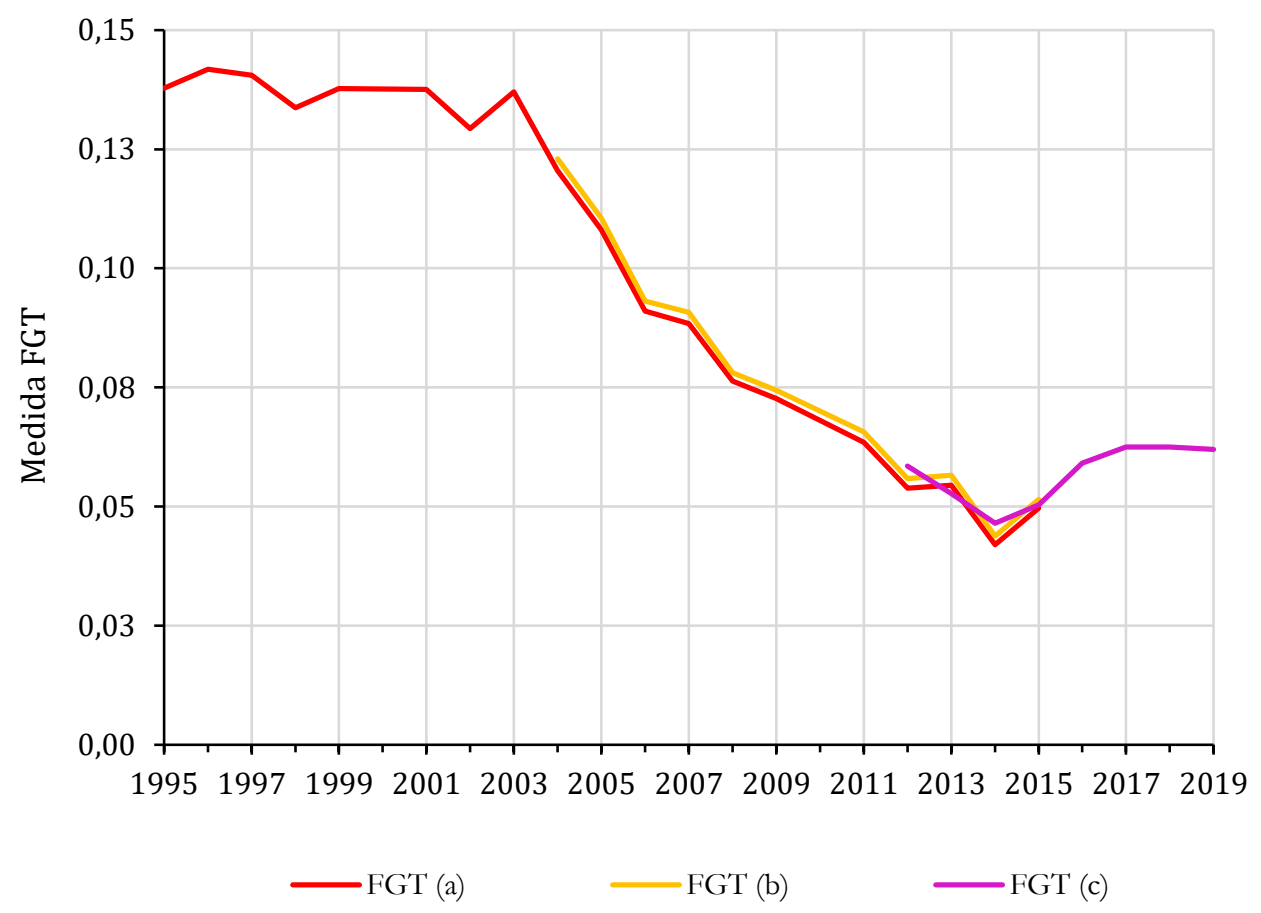

Figura 16. Evolução da proporção de pobres $(H)$ e da medida $H I=F G T(1)$, linha de pobreza de $R \$ 200$ (em $\mathrm{R} \$$ do $4^{\circ}$ trimestre de 2019), Brasil, 1995-2019

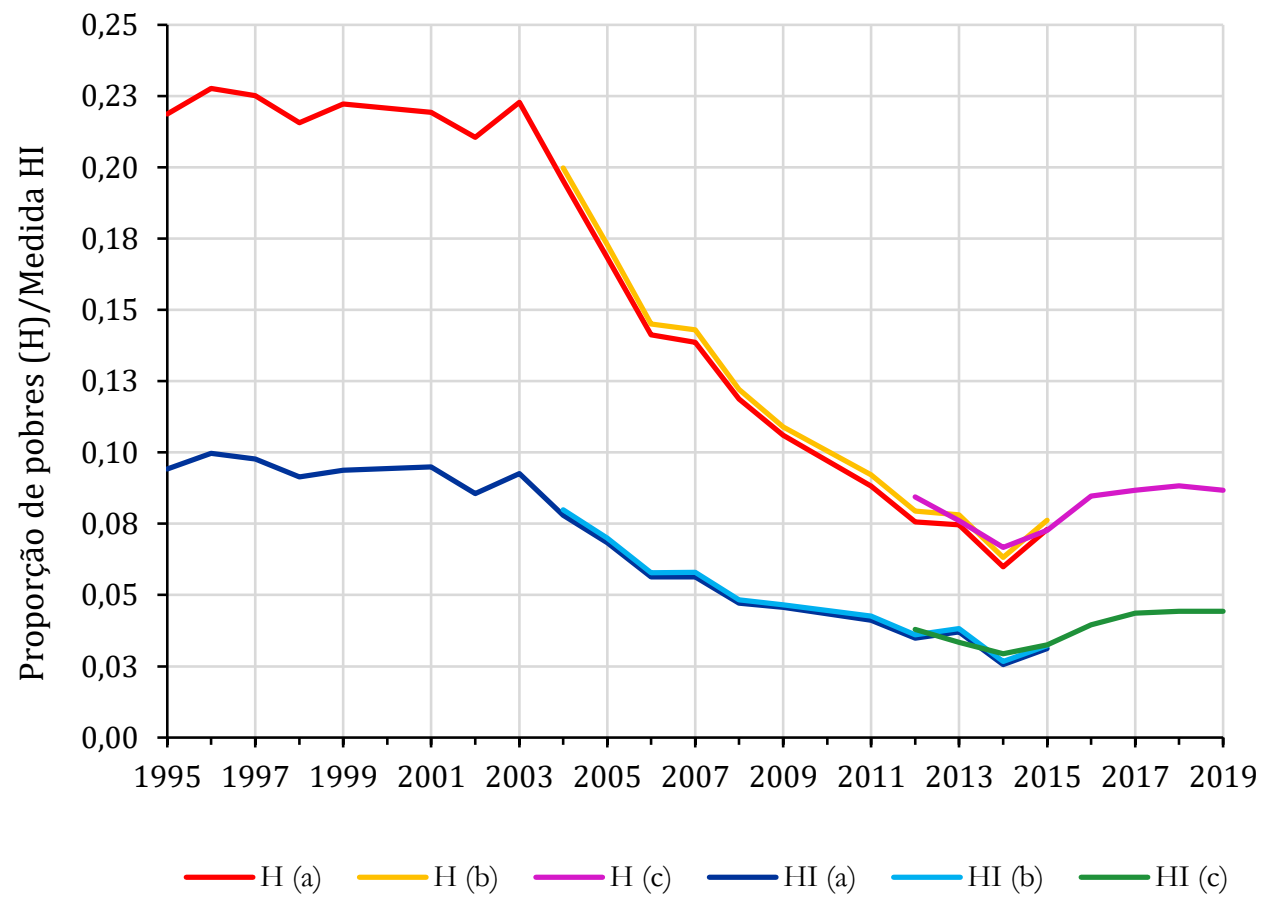


Figura 17. Evolução do índice de pobreza FGT adotando uma linha de pobreza de R\$200 (em $\mathrm{R} \$$ do $4^{\circ}$ trimestre de 2019), Brasil, 1995-2019

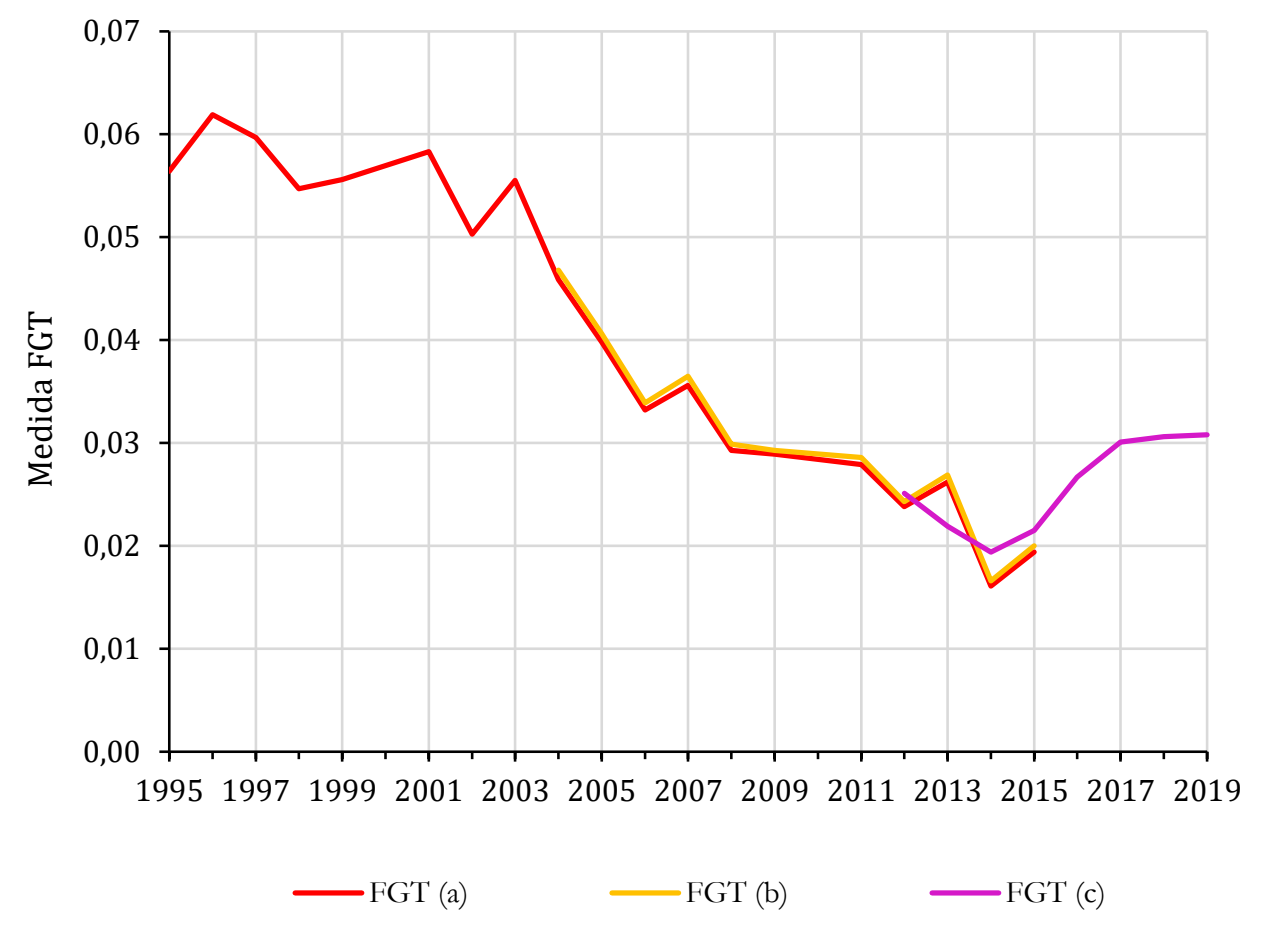

\subsection{A distribuição do rendimento do trabalho entre pessoas ocupadas e entre pessoas} economicamente ativas de 1995 a 2019

Nesta seção apresenta-se a evolução das principais características da distribuição do rendimento do trabalho na POC e na PEA, considerando as séries (a), (b) e (c) já definidas.

As Figuras 18 e 19 mostram a evolução dos rendimentos médios e medianos, respectivamente. Observa-se, novamente, que a exclusão da área rural da antiga região norte tem pouquíssimo efeito nos resultados. As duas figuras mostram, também, a evolução do dobro do valor real do salário mínimo, para facilitar a comparação com o comportamento dos rendimentos médio e mediano. Cabe lembrar que a evolução do valor real do salário mínimo já foi apresentada nas Figuras 9 e 10, sendo que para o período 1995-2015, referente à PNAD tradicional, considera-se o seu valor real em setembro-outubro de cada ano e para o período 2012-2019, referente à PNAD Contínua, mostra-se a evolução do seu valor real no quarto trimestre de cada ano.

É interessante notar que no período 1999-2014, durante o qual a taxa de desemprego mostrou tendência decrescente, mas sem saltos muito fortes, a evolução do rendimento médio na PEA é semelhante à evolução do rendimento médio na POC; então, a evolução do mercado de trabalho não era tão distorcida se a análise se limitasse à POC. Mas, 
de 2014 a 2017 a queda no rendimento médio na PEA é muito mais intensa do que a queda no rendimento médio na POC, pois a taxa de desemprego sobe de $7 \%$ para $13 \%$.

Figura 18. Evolução do rendimento médio para POC e para PEA e do dobro do salário mínimo (SM) (em $\mathrm{R} \$$ do $4^{0}$ trimestre de 2019), Brasil, 1995-2019

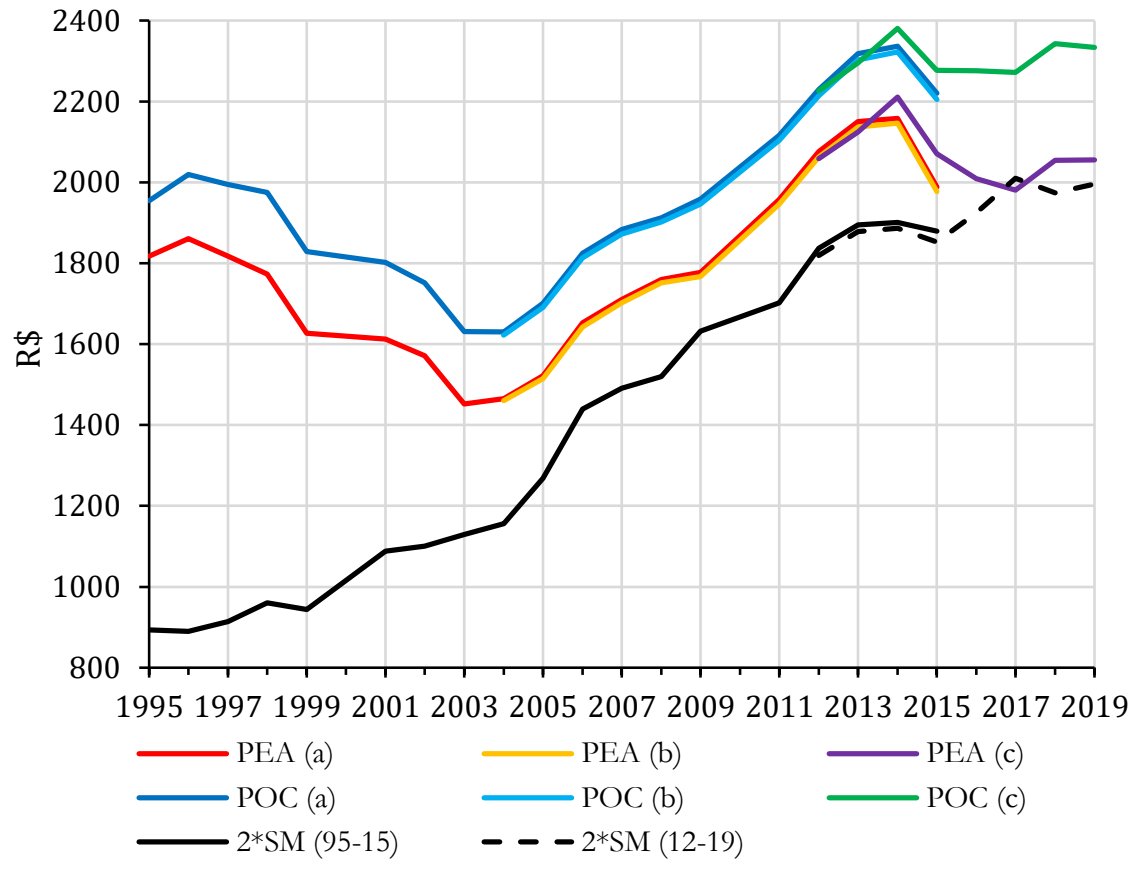

Figura 19. Evolução do rendimento mediano para POC e para PEA e do salário mínimo (SM) (em $\mathrm{R} \$$ do $4^{0}$ trimestre de 2019), Brasil, 1995-2019

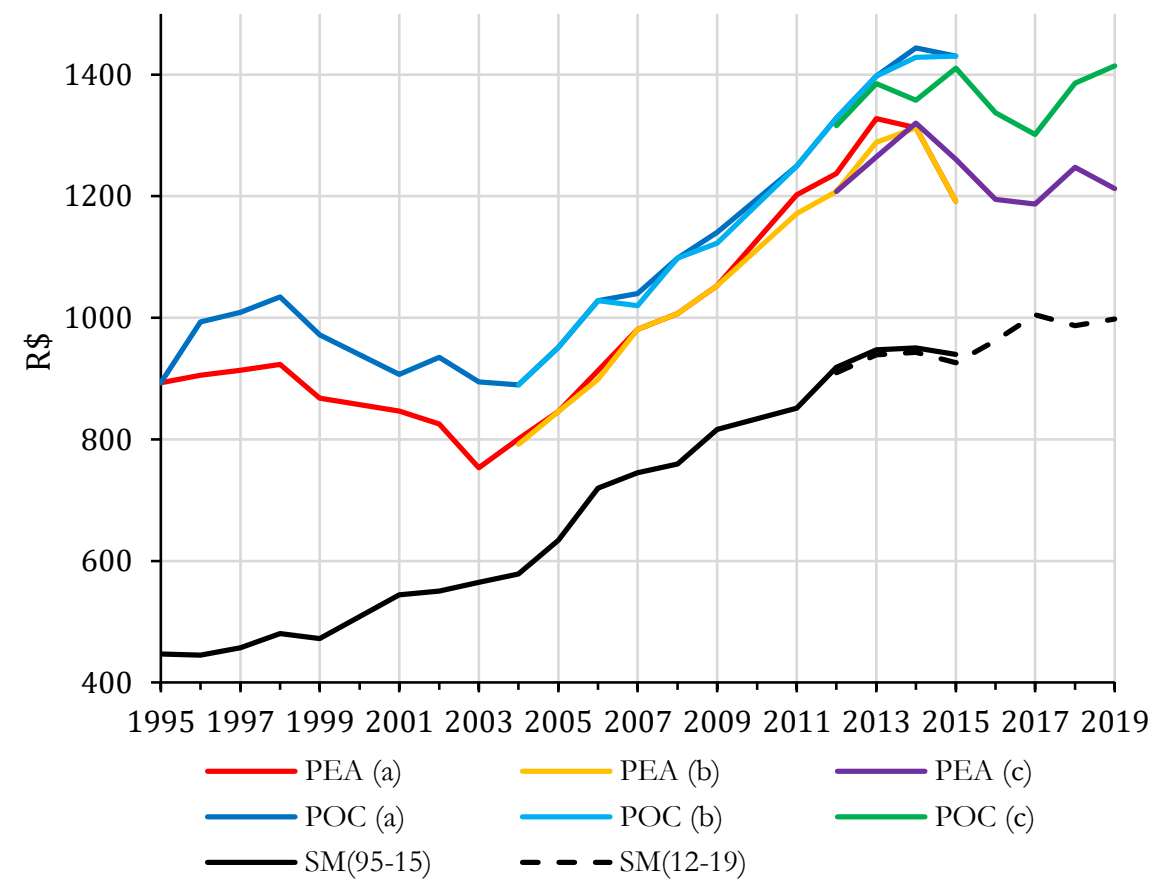


As Figuras 20, 21 e 22 mostram a evolução da desigualdade da distribuição do rendimento do trabalho na POC e na PEA. Como já discutido anteriormente, a PNADC permite captar mais desigualdade do que a PNAD tradicional, fazendo que quase sempre, no período 2012-2015, a medida de desigualdade para a série (c) seja maior do que a da série (b).

No período 1995-1999 a taxa de desemprego subiu de $7 \%$ para $11 \%$, fazendo com que a queda da desigualdade na POC não fosse acompanhada pela desigualdade na PEA; no caso da razão de médias 10+/40- (ver Figura 22), ocorre redução do valor na POC e aumento na PEA nesse período. O comportamento das desigualdades na PEA e na POC volta a ser nitidamente diferente no período 2014-2017, quando o enorme crescimento do desemprego leva a um aumento muito maior da desigualdade na PEA.

Figura 20. Evolução do índice de Gini da distribuição do rendimento do trabalho para POC e para PEA Brasil, 1995-2019

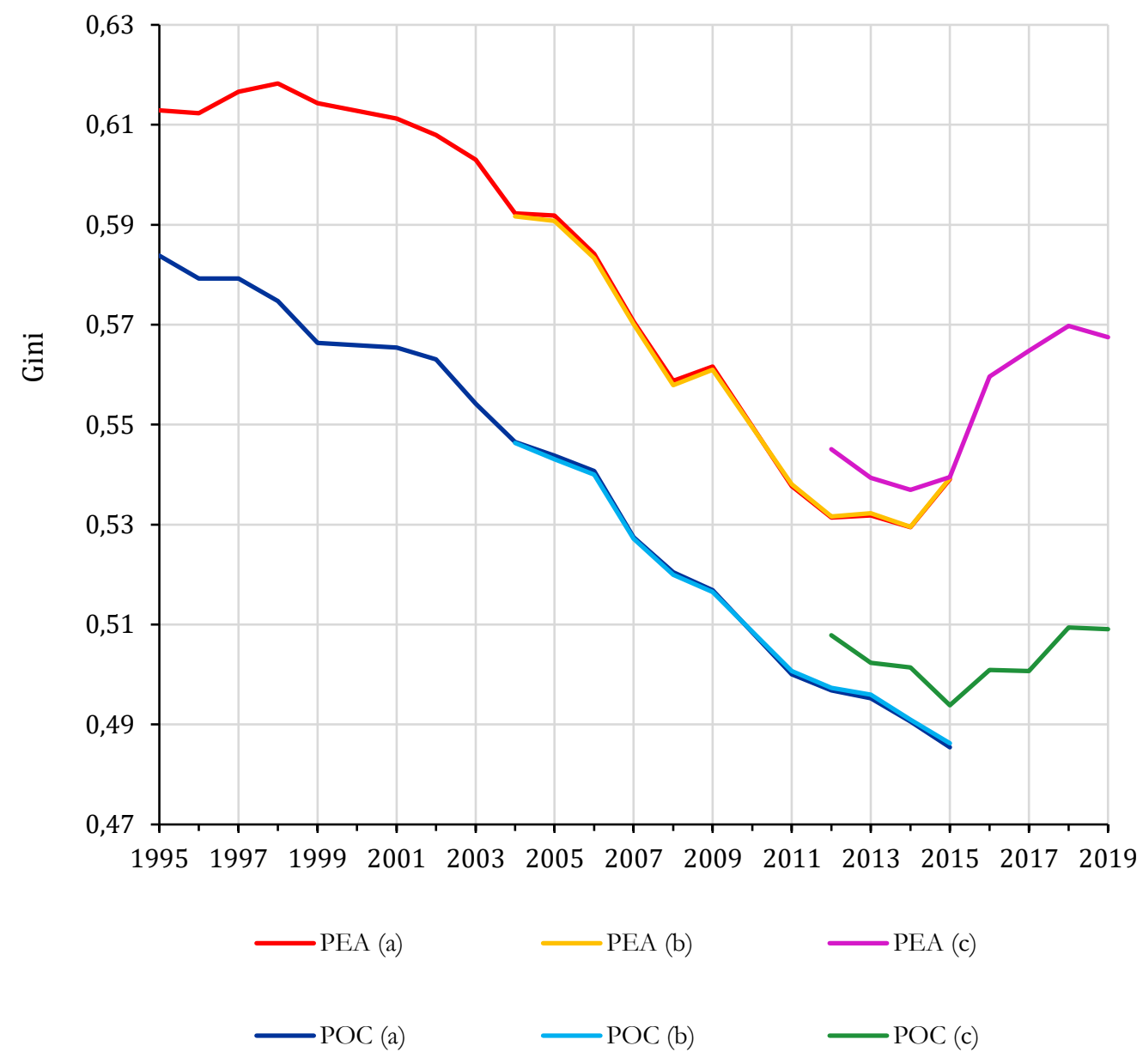


Figura 21. Evolução da medida T de Theil da distribuição do rendimento do trabalho para POC e para PEA Brasil, 1995-2019

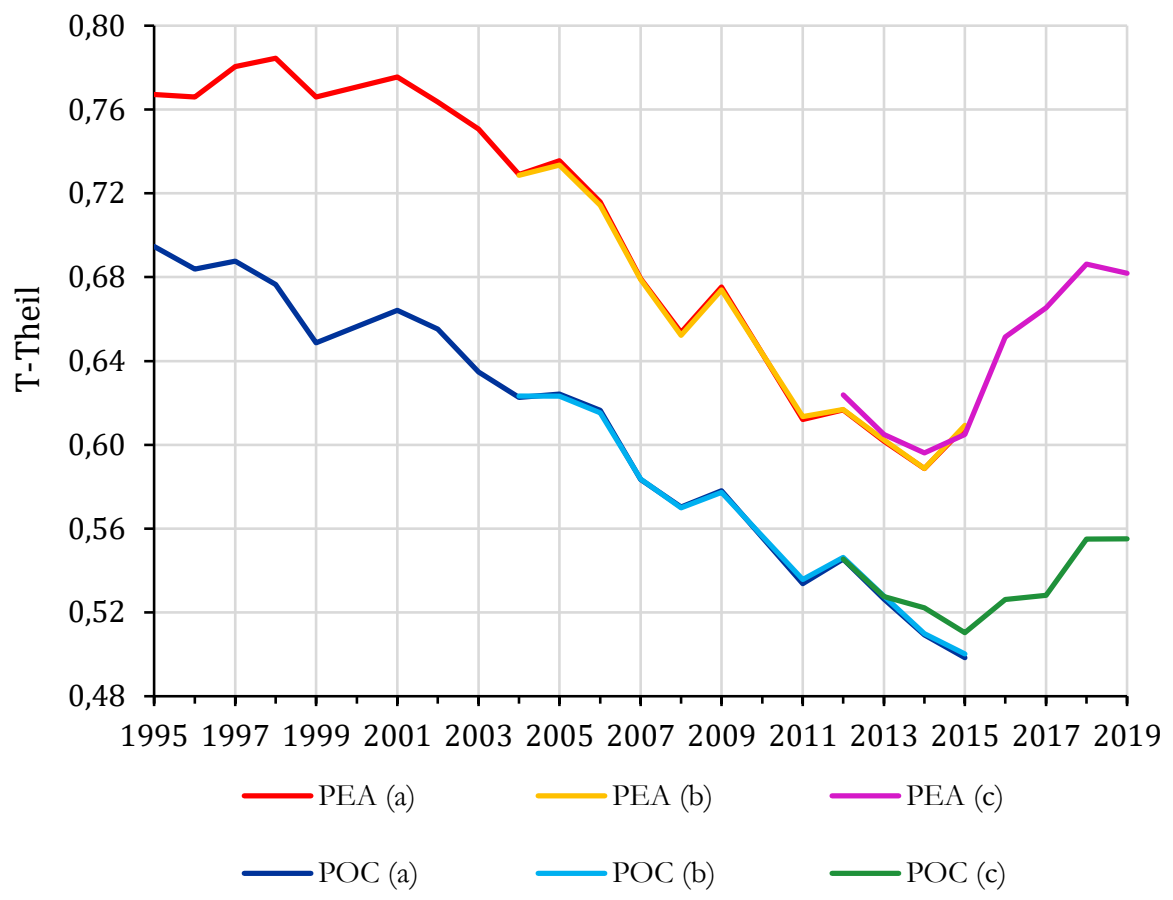

Figura 22. Evolução da razão de médias $10+/ 40$ - da distribuição do rendimento do trabalho para POC e para PEA, Brasil, 1995-2019

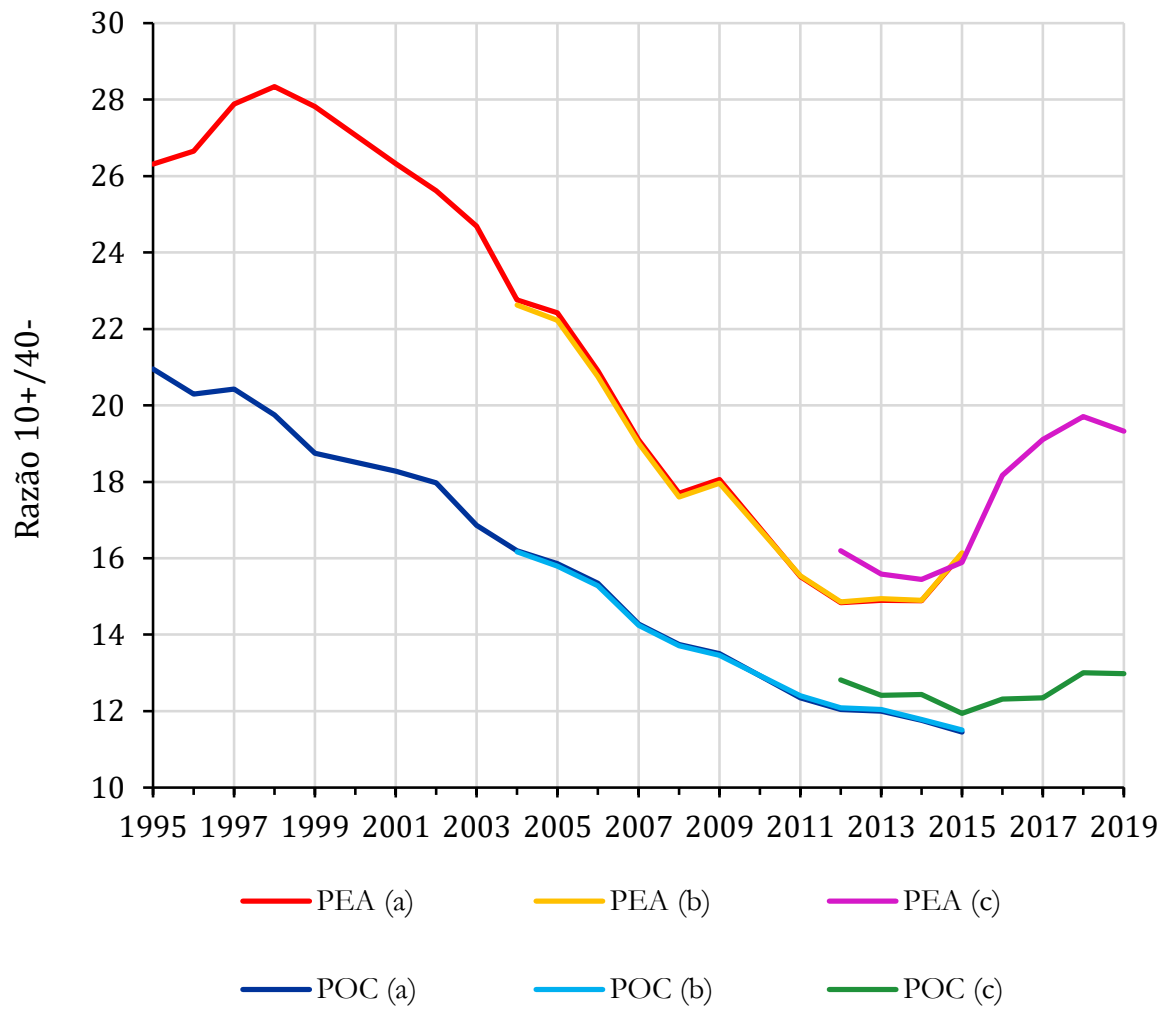


Examinando o conjunto de figuras referentes à evolução da desigualdade da distribuição da RDPC (Figuras 11 e 12) e da desigualdade da distribuição da renda do trabalho (Figuras 20, 21 e 22), nota-se como a análise restrita à POC "esconde" o aumento da desigualdade quando ocorre aumento do desemprego. Por outro lado, as medidas de desigualdade da distribuição da renda do trabalho na PEA tendem a mostrar, durante a crise econômica, um crescimento mais intenso do que as da distribuição da RDPC, certamente porque outras rendas, especialmente as transferências (Bolsa-Família, Benefício de Prestação Continuada e outras), têm um efeito amortecedor. ${ }^{8}$

As Figuras 23 e 24 mostram a evolução da proporção de pobres e da medida FGT na POC e na PEA, para uma linha de pobreza de $\mathrm{R} \$ 420$ por mês (em reais do quarto trimestre de 2019). Como explicado anteriormente, essa linha de pobreza fica, ao longo de todo o período, abaixo do valor do salário mínimo.

Figura 23. Evolução da proporção de pobres $(\mathrm{H})$ na distribuição do rendimento do trabalho para POC e para PEA, adotando uma linha de pobreza de $R \$ 420$ (em R\$ do $4^{\circ}$ trimestre de 2019) Brasil, 1995-2019

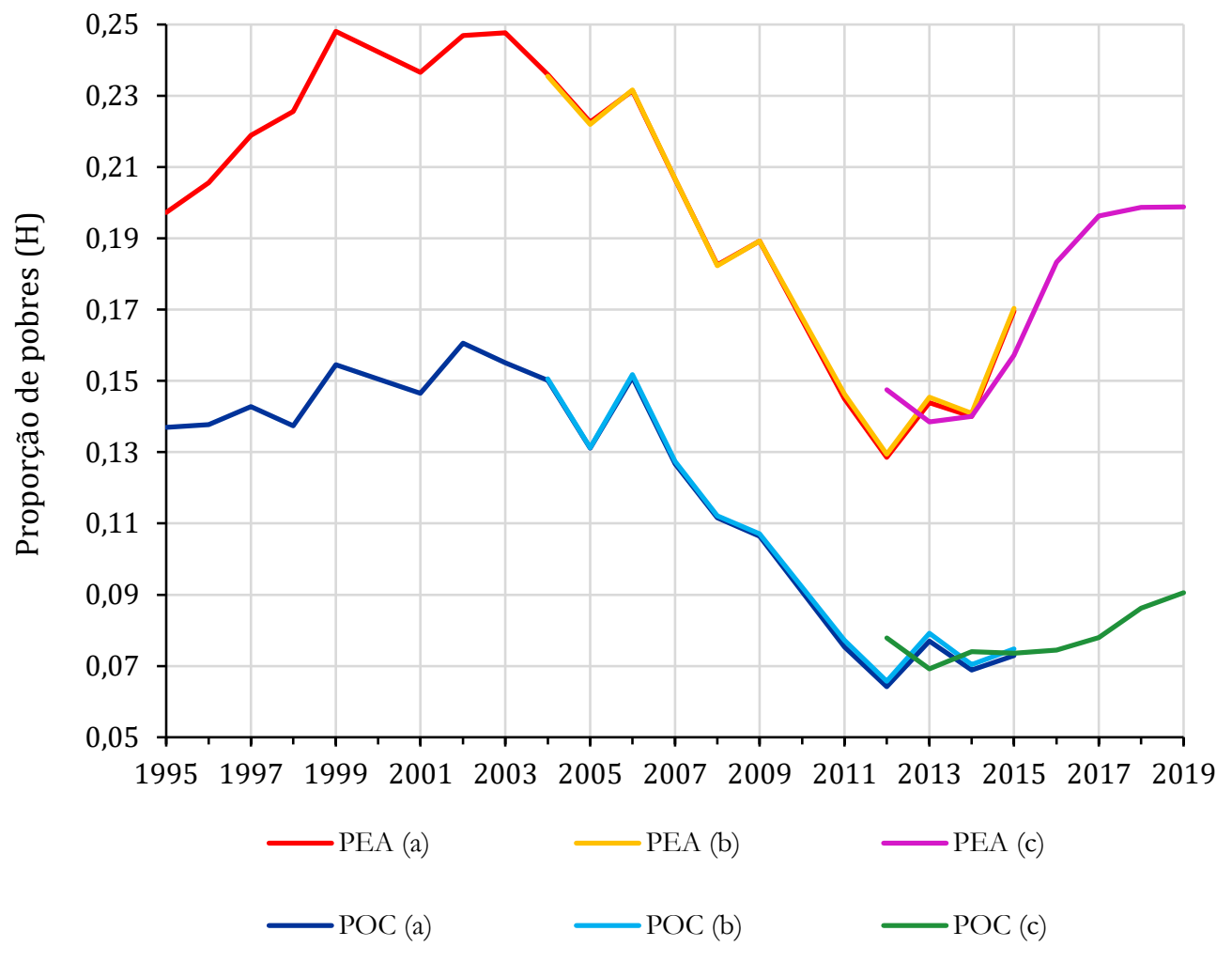

${ }^{8} \mathrm{~A}$ análise de como diferentes parcelas da RDPC contribuem para a desigualdade da distribuição pode ser encontrada em Hoffmann (2020b) e Hoffmann e Vaz (2020). Cabe ressaltar que aposentadorias e pensões pagas pelo INSS são progressivas (contribuem para reduzir a desigualdade), mas as de funcionários públicos estatutários são regressivas. 
Figura 24. Evolução da medida de pobreza de Foster, Greer e Thorbecke (FGT) da distribuição do rendimento do trabalho para POC e para PEA, Brasil, 1995-2019

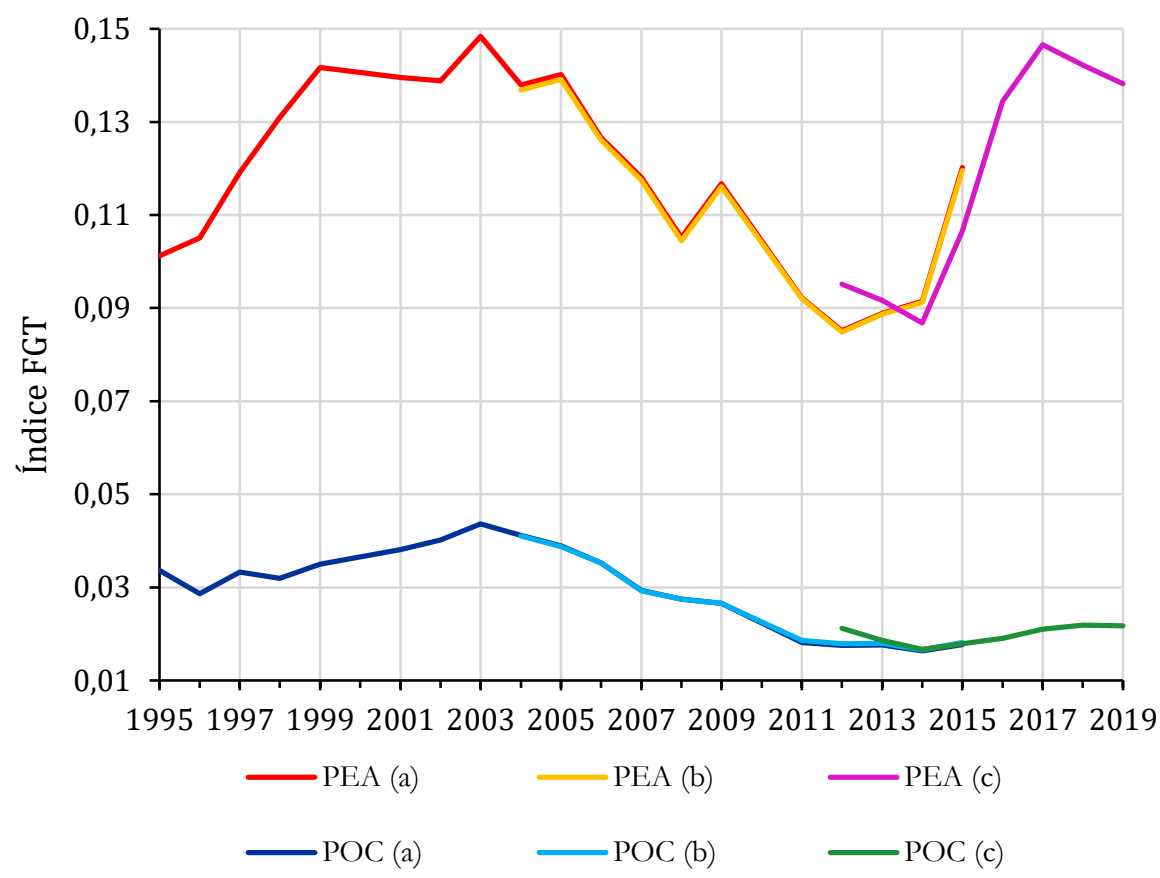

Observa-se que tanto no período 1995-1999 quanto no período 2014-2017, nos quais ocorreu grande crescimento do desemprego, o comportamento da medida de pobreza para a PEA é claramente mais desfavorável do que para a POC.

Sem perder de vista todas as diferenças metodológicas entre uma medida de pobreza baseada na RDPC e outra baseada no rendimento do trabalho para POC ou PEA, é interessante comparar os resultados ilustrados nas Figuras 17 e 24. Para avaliação do bemestar da população, certamente é mais apropriado utilizar a RDPC e, nesse sentido, a Figura 17 pode ser tomada como base de comparação. Comparando, particularmente, o comportamento da medida FGT nas duas figuras no período 2014-2017, percebe-se que a medida baseada na POC "esconde" o aumento da pobreza e a baseada na PEA "exagera" esse aumento.

\section{Conclusão}

Análises da distribuição da renda precisam especificar claramente o tipo de renda e a população considerada. Nesta pesquisa foi analisada a evolução, no Brasil, de 1995 a 2019, de três diferentes distribuições: da renda domiciliar per capita (RDPC) e do rendimento do trabalho entre pessoas ocupadas (POC) e entre pessoas economicamente ativas (PEA). Ficam evidentes fenômenos já estabelecidos na literatura sobre o tema, como a substancial redução da desigualdade e da pobreza nos primeiros 14 anos do novo milênio. Confirma-se, 
também, a inversão desse processo, com intenso crescimento da desigualdade e da pobreza de 2014 a 2017. Fica claro que a limitação da análise à distribuição na POC não revela com clareza esse aumento recente da desigualdade e da pobreza. Mas isso não significa que não se devam desenvolver pesquisas focadas na POC. A estimação de equações de rendimento, por exemplo, cuja variável dependente é, usualmente, o logaritmo do rendimento do trabalho, fica limitada às pessoas ocupadas com rendimento positivo. O que se pode recomendar é que toda análise da POC seja complementada com dados sobre desemprego e características da distribuição da renda na PEA.

\section{Referências}

Almeida, S. S. P. (2019). Evolução da distribuição de renda no Brasil de 1995 a 2017. (Dissertação de Mestrado). ESALQ, Universidade de São Paulo (USP), Piracicaba, Brasil. https://www.teses.usp.br/teses/disponiveis/11/11132/tde-17012020-173805/pt-br.php

Andrada, A. F. S., \& Boianovsky, M. (2020). The political economy of the income distribution controversy in 1970s Brazil: debating models and data under military rule. In Research in the history of economic thought and methodology: Including a Symposium on Economists and Authoritarian Regimes in the 20th Century (vol. 38B, cap. 5, pp. 75-94). Emerald Publishing Limited. http://doi.org/10.1108/S0743-41542020000038B005

Barbosa, R. J. (2019). Estagnação desigual: desemprego, desalento, informalidade e a distribuição da renda do trabalho no período recente (2012-2019). Mercado de Trabalho: conjuntura e análise (Boletim do IPEA), 25(67), 59-70.

http://repositorio.ipea.gov.br/bitstream/11058/9949/1/bmt 67 nt estagnacao desigual de semprego.pdf

Hoffmann, R. (2020a). Distribuição da renda domiciliar per capita no Brasil, 2012 a 2019 e 1995 a 2015. [Texto para Discussão n. 59], Instituto de Estudos de Política Econômica/ Casa das Garças (IEPE/CdG), Rio de Janeiro, Brasil. https://iepecdg.com.br/wpcontent/uploads/2020/05/RDPC1995-2019.pdf

Hoffmann, R. (2020b). Parcelas regressivas e progressivas da renda domiciliar per capita e fatores associados à desigualdade da distribuição da renda no Brasil, 2012-2019. [Texto para Discussão n. 62], IEPE/CdG, Rio de Janeiro, Brasil. https://iepecdg.com.br/wpcontent/uploads/2020/06/RDPC 11 PARCELAS 2012-19-2.pdf

Hoffmann, R., Botassio, D. C., \& Jesus, J. G. (2019). Distribuição de renda: medidas de desigualdade, pobreza, concentração, segregação e polarização. São Paulo: Editora da Universidade de São Paulo.

Hoffmann, R., Jesus, J. G., \& Almeida, S. S. P. (2018). A distribuição da renda no Brasil conforme a PNAD: 1995-2017. [Texto para Discussão n. 45], Instituto de Estudos de Política Econômica/Casa das Garças (IEPE/CdG), Rio de Janeiro, Brasil. (Nova versão de maio/2019 incluindo anexo com resultados para rendimentos habituais). https://iepecdg.com.br/wpcontent/uploads/2018/08/PNAD9517H-1.pdf 
Hoffmann, R., \& Vaz, D. V. (2020). Mensurando a desigualdade no Brasil: evidências a partir da renda e dos gastos das famílias. [Texto para Discussão n. 63], Instituto de Estudos de Política Econômica/Casa das Garças (IEPE/CdG), Rio de Janeiro, Brasil.

https://iepecdg.com.br/wp-content/uploads/2020/06/DESIGUALDADE POF2017-18.pdf

Instituto Brasileiro de Geografia e Estatística (IBGE) (2014a). Pesquisa Nacional por Amostra de Domicílios, 2013 (vol. 33). Rio de Janeiro, Brasil.

https://biblioteca.ibge.gov.br/visualizacao/periodicos/59/pnad 2013 v33 br.pdf

Instituto Brasileiro de Geografia e Estatística (IBGE) (2014b). Pesquisa Nacional por Amostra de Domicílios Contínua. Notas Metodológicas (vol. 1). Rio de Janeiro, Brasil.

ftp://ftp.ibge.gov.br/Trabalho e Rendimento/Pesquisa Nacional por Amostra de Domicilio s continua/Notas metodologicas/notas metodologicas.pdf

Recebido em 06 de julho de 2020.

Aprovado em 29 de julho de 2020. 